\title{
The DILfrequency study is an adaptive trial to identify optimal IL-2 dosing in patients with type 1 diabetes
}

Eleonora Seelig, ${ }^{1,2,3,4}$ James Howlett, ${ }^{3,5,6}$ Linsey Porter, ${ }^{1,3,4}$ Lucy Truman,,,$^{3,4,7}$ James Heywood, ${ }^{1,3,4}$ Jane Kennet,, ${ }^{1,2,3,4}$ Emma L. Arbon, ${ }^{3,6}$ Katerina Anselmiova, ${ }^{1,2,3,4}$ Neil M. Walker, ${ }^{3,4,8}$ Ravinder Atkar, ${ }^{3,9}$ Marcin L. Pekalski, ,3,10 Ed Rytina, ${ }^{3,11}$ Mark Evans,, ${ }^{2,3}$ Linda S. Wicker, ${ }^{3,4,10}$ John A. Todd, ${ }^{3,4,10}$ Adrian P. Mander, ${ }^{3,5}$ Simon Bond,, ${ }^{3,5,6}$ and Frank Waldron-Lynch 1,2,3,4,6

${ }^{1}$ Experimental Medicine and Immunotherapeutics, Department of Medicine, ${ }^{2}$ Wellcome Trust-MRC Institute of Metabolic Science, and ${ }^{3}$ National Institute for Health Research, Cambridge Biomedical Research Centre, Addenbrooke's Hospital, University of Cambridge, Cambridge, United Kingdom. ${ }^{4}$ JDRF/Wellcome Trust Diabetes and Inflammation Laboratory and ${ }^{5}$ MRC Biostatistics Unit Hub for Trials Methodology Research, Cambridge Institute of Public Health, University of Cambridge, Cambridge, United Kingdom. ${ }^{6}$ National Institute for Health Research, Cambridge Clinical Trials Unit, ${ }^{7}$ Department of Ear, Nose, and Throat Surgery, ${ }^{8}$ Department of Clinical Informatics, and ${ }^{9}$ Department of Dermatology, Cambridge University Hospitals NHS Foundation Trust, Addenbrooke's Hospital, Cambridge Biomedical Campus, Cambridge, United Kingdom. ${ }^{10}$ DRR/Wellcome Diabetes and Inflammation Laboratory, Wellcome Trust Center for Human Genetics, Nuffield Department of Medicine, University of Oxford, Oxford, United Kingdom. "Department of Pathology, Cambridge University Hospitals NHS Foundation Trust, Addenbrooke's Hospital, Cambridge Biomedical Campus, Cambridge, United Kingdom.

BACKGROUND. Type 1 diabetes (T1D) results from loss of immune regulation, leading to the development of autoimmunity to pancreatic $\beta$ cells, involving autoreactive T effector cells (Teffs). Tregs, which prevent autoimmunity, require IL-2 for maintenance of immunosuppressive functions. Using a response-adaptive design, we aimed to determine the optimal regimen of aldesleukin (recombinant human IL-2) to physiologically enhance Tregs while limiting expansion of Teffs.

METHODS. DILfrequency is a nonrandomized, open-label, response-adaptive study of participants,

Role of funding source: The funding bodies had no role in the study design, data collection and analysis, decision to publish, or preparation of the manuscript.

Conflict of interest: FWL led the CamT1D team, which received research and clinical trial funding from HoffmannLa Roche and ClaxoSmithKline. FWL is currently employed by Novartis. JAT has received advisory board fees from Pfizer, Celgene, and AstraZeneca.

License: This work is licensed under the Creative Commons Attribution 4.0 International License. To view a copy of this license, visit http:// creativecommons.org/licenses/ by/4.0\%.

Submitted: December 21, 2017

Accepted: August 21, 2018

Published: October 4, 2018

\section{Reference information:}

JCI Insight. 2018;3(19):e99306.

https://doi.org/10.1172/jici.

insight.99306. aged 18-70 years, with T1D. The initial learning phase allocated 12 participants to 6 different predefined regimens. Then, 3 cohorts of 8 participants were sequentially allocated dose frequencies, based on repeated interim analyses of all accumulated trial data. The coprimary endpoints were percentage change in Tregs and Teffs and CD25 ( $\alpha$ subunit of the IL-2 receptor) expression by Tregs, from baseline to steady state.

RESULTS. Thirty-eight participants were enrolled, with thirty-six completing treatment. The optimal regimen to maintain a steady-state increase in Tregs of $30 \%$ and CD25 expression of $25 \%$ without Teff expansion is $0.26 \times 10^{6} \mathrm{IU} / \mathrm{m}^{2}(95 \% \mathrm{Cl}-0.007$ to 0.485$)$ every 3 days. Tregs and CD25 were dose-frequency responsive, Teffs were not. The commonest adverse event was injection site reaction (464 of 694 events).

CONCLUSIONS. Using a response-adaptive design, aldesleukin treatment can be optimized. Our methodology can generally be employed to immediately access proof of mechanism, thereby leading to more efficient and safe drug development.

TRIAL REGISTRATION. International Standard Randomised Controlled Trial Number Register, ISRCTN40319192; ClinicalTrials.gov, NCT02265809.

FUNDING. Sir Jules Thorn Trust, the Swiss National Science Foundation, Wellcome, JDRF, and NIHR Cambridge Biomedical Research Centre. 


\section{Introduction}

Type 1 diabetes (T1D) is a common chronic disease of children and adults; yet, despite a large investment by both the pharmaceutical industry and academic research communities, insulin replacement remains the only treatment $(1,2)$. Although, insulin is lifesaving through correction of insulinopenia and resolution of hyperglycemia, it does not treat the underlying autoimmune-mediated destruction of the insulin-producing $\beta$ cells in the pancreatic islets (3). To improve short-term and long-term clinical outcomes (4), there is a need to develop treatments that preserve endogenous insulin production.

Clinical trials of several immunosuppressive agents in T1D demonstrated proof of concept by transiently preserving $\beta$ cell function, yet others had no effect or led to disease progression, possibly due to incorrect dose selection $(5,6)$. These results, combined with their side effect profiles, their potential use in the pediatric population, and the requirement for prolonged immunosuppression have prevented the entry of these drugs into clinical practice to treat or prevent T1D. The development of a new nonimmunosuppressive therapy that targets the underlying autoimmune cause of T1D would represent an advance on the current standard.

IL-2 is a growth factor, produced by $\mathrm{CD}^{+} \mathrm{T}$ effector cells (Teffs) that binds with high affinity to the heterotrimeric IL-2 receptor, which includes the $\alpha$ subunit (CD25) (7). CD25 is preferentially expressed by IL-2-dependent CD4 ${ }^{+}$Tregs. Tregs have an absolute requirement for IL-2 to survive and maintain regulation of Teff responses, thereby preventing autoimmunity or collateral tissue damage during immune responses (8). In T1D, genetic studies have found that several of the genes in the IL-2 pathway contribute to susceptibility, while gene-phenotype studies have found that lower expression of CD25 on the surface of Teffs and Tregs is correlated with increased risk of disease (9). Thus, physiological replacement of IL-2 in T1D to mimic the protection afforded by the risk-reducing alleles of the IL-2 pathway genes could restore Treg-mediated immune regulation while avoiding immune activation.

High-dose recombinant IL-2 (aldesleukin) treatment protocols were originally developed to treat metastatic renal carcinoma and melanoma by activating and increasing the numbers of Teffs and NK cells (10, 11). More recently, proof-of-concept trials of low-dose aldesleukin have shown some clinical efficiency in chronic graft-versus-host disease (cGVHD), hepatitis $\mathrm{C}$, alopecia areata, and systemic lupus erythematosus (12-15). In T1D, therapy with low-dose aldesleukin alone has been shown to be safe (16), though in combination with rapamycin it caused disease progression (17). Many of these studies share an initial induction phase of daily or alternate day dosing that is modeled on the oncology protocols that were developed using standard trial methodologies.

In the previously published DILT1D trial, we employed a state-of-the-art adaptive-dose finding design to define 2 single doses of aldesleukin that increased frequencies of Tregs by $10 \%$ and $20 \%\left(0.101 \times 10^{6}\right.$ and $\left.0.497 \times 10^{6} \mathrm{IU} / \mathrm{m}^{2}\right)(18)$. In addition, we found that Tregs were desensitized for at least 24 hours after drug administration and that single doses over $0.380 \times 10^{6} \mathrm{IU} / \mathrm{m}^{2}$ did begin to activate Teffs. Based on these results, we hypothesized that daily dosing was not optimal to maintain a Treg increase within the physiological range without Teff expansion. We speculated that a favorable interval might be greater than every 2 days but not as much as 7 or 14 days.

The next step in this experimental medicine program was to establish the optimal dose and frequency of aldesleukin administration that would achieve sustained, increased Treg responses without increasing Teff frequencies. To determine the optimal regimen of aldesleukin, we used a response-adaptive repeat dose trial design.

\section{Results}

Between November 17th 2014 and May 22nd 2016, 38 participants were enrolled at the National Institute for Health Research (NIHR) Wellcome Trust Clinical Research Facility at Addenbrooke's Hospital, Cambridge, United Kingdom (Figure 1). The baseline characteristics of the safety population $(n=37)$ are presented in Table 1. When cohort 1 (12 participants) completed the first learning phase, a second learning phase was conducted, as not enough participants in the trial had achieved steady state for the primary endpoints. Cohort 2 ( 8 participants) was treated with 2 doses of 0.09 and $0.47 \times 10^{6} \mathrm{IU} / \mathrm{m}^{2}$ aldesleukin at frequencies of between 3 and 10 days. As shown in Figure 2A, the treatment duration and timing of assessments depended on frequency of the drug administration. For example, a participant receiving 0.09 $\times 10^{6} \mathrm{IU} / \mathrm{m}^{2}$ aldesleukin every 2 days had study visits every 2 days, which led to a relatively short treatment duration of 14 days, with a total study duration of 44 days. A participant on the same dose administered 
every 14 days had assessments every 7 days and a treatment duration of 56 days and was enrolled in the study for 98 days. After the second learning phase, the dose frequency committee (DFC) determined that steady state had been achieved in enough participants to set a Treg target of a $30 \%$ increase (range $\pm 5 \%$ ), a CD25 target of a $25 \%$ increase (range $\pm 5 \%$ ), and a Teff target of a $0 \%$ increase/decrease (range $-100 \%$ to $\infty$ ) from baseline for remainder of the trial. For the confirming phase of the trial, doses of $0.2 \times 10^{6} \mathrm{IU} /$ $\mathrm{m}^{2}$ or $0.32 \times 10^{6} \mathrm{IU} / \mathrm{m}^{2}$ every 3 days were allocated to cohort 3 (8 participants) (Figure $2 \mathrm{~B}$ ), with a dose of $0.32 \times 10^{6} \mathrm{IU} / \mathrm{m}^{2}$ every 3 days allocated to the final cohort (8 participants) (Figure $2 \mathrm{C}$ ). Dose and frequency allocations according to cohort and population, respectively, are shown in Supplemental Tables 1 and 2 (supplemental material available online with this article; https://doi.org/10.1172/jci.insight.99306DS1).

There were no serious adverse events (AEs) reported in the trial, with 37 (100\%) of participants reporting an AE (Table 2). All the AEs were mild (670 of 694, 96.5\%) or moderate (24 of $694,3.5 \%$ ), with the most common being hypoglycemia, injection site nodule, and injection site erythema (Table 2 and Supplemental Table 3). A single participant on a dose of $0.47 \times 10^{6} \mathrm{IU} / \mathrm{m}^{2}$ every 4 days developed an asymptomatic eosinophilia on visit 7 that resolved by visit 11 . Preexisting eosinophilia improved by visit 11 or even resolved by visit 10 in 2 participants receiving $0.32 \times 10^{6} \mathrm{IU} / \mathrm{m}^{2}$ every 3 days and $0.09 \times 10^{6} \mathrm{IU} / \mathrm{m}^{2}$ every 2 days, respectively (Supplemental Figure 1). In some participants (21 of 37, 56.8\%) there were transient decreases in lymphocytes at 90 minutes after the first dose and again after the second (11 of 20,55.0\%) or tenth dose (11 of $16,68.8 \%$ ), without the development of lymphopenia. There was no evidence of the development of thyroid dysfunction, despite enrolling participants with positive anti-TPO antibodies ( 8 of $36,22.2 \%$ ), with no participants developing de novo anti-TPO or anti-TSH antibodies following treatment (Supplemental Figure 2). Aldesleukin had no effect on hsCRP, renal, bone, or liver biochemistry and clinical FACS parameters (Supplemental Tables 4 and 5). One participant with stable psoriasis was treated with $0.32 \times 10^{6} \mathrm{IU} / \mathrm{m}^{2}$ every 3 days without any exacerbating of preexisting disease (Supplemental Figure 3 ). Overall, treatment was well tolerated at all doses and frequencies, with no participants discontinuing the study or being withdrawn by the trial team due to AEs or reactions.

In the analysis population, the model that included the effect of dose, dosage frequency, dosage frequency squared, and the dose frequency interaction fitted the data best with the smallest combined Akaike information criterion of 696.92 . The model explained $50.35 \%$ of the variability in Tregs $(P=0.0022), 76.12 \%$ of the variability in $\mathrm{CD} 25(P<0.0001)$, and $37.32 \%$ of the variability in Teffs $(P=0.0246)$. The optimal dose of aldesleukin is $0.26 \times 10^{6} \mathrm{IU} / \mathrm{m}^{2}(95 \% \mathrm{CI}-0.007,0.485)$ every 3 days $(95 \%$ CI $1.3,4.4)$. The probability of this treatment regime achieving the targets for the 3 endpoints is 0.742 or $74.2 \%$ (Figure 3 and Supplemental Tables 6-8). The analysis for the evaluable population is shown in Supplemental Table 9.

Analysis of the 3-day dosing interval found that the $0.47 \times 10^{6} \mathrm{IU} / \mathrm{m}^{2}$ and $0.32 \times 10^{6} \mathrm{IU} / \mathrm{m}^{2}$ doses produced similar mean Treg increases of $41.31 \%(n=2)$ and $45.87 \% \pm 22.43 \%(n=8)$, respectively, at the primary endpoint when administered every 3 days, while the $0.20 \times 10^{6} \mathrm{IU} / \mathrm{m}^{2}$ dose increased Tregs $20.34 \%$ $\pm 11.05 \%(n=4)$ (Figure 4, A-C). A maximum increase in Tregs of $83.67 \%$ from baseline was observed on visit 9 after 8 doses of $0.32 \times 10^{6} \mathrm{IU} / \mathrm{m}^{2}$ every 3 days. This increase was maintained up to visit 11 to give an overall mean increase of $79.59 \%$ for the primary endpoint in this participant (Figure $4, \mathrm{~B}$ and $\mathrm{C}$ ). The lowest dose, $0.09 \times 10^{6} \mathrm{IU} / \mathrm{m}^{2}$, was only effective in increasing Tregs when administered every 2 days; wider dosing intervals with this dose had no effect (Figure 4, A-C, and Supplemental Figures 15-18). At the 5-day interval, only the highest dose of $0.47 \times 10^{6} \mathrm{IU} / \mathrm{m}^{2}$ was effective in maintaining a Treg increase of $23.28 \%(n=2)$, becoming a no-effect dose at 10 or 14 days (Figure $4 \mathrm{C}$ ).

The expression of CD25 increased on Tregs, with the maximal response by dose seen at dose $6.1 \pm 2.3$ $(n=15)$ at 3-day dose intervals (Figure 4, D-F, and Supplemental Figures 17 and 18). At the 3-day interval, the lowest dose failed to maintain an increase of Treg CD25 expression at steady state, while the $0.20,0.32$, and $0.47 \times 10^{6} / \mathrm{m}^{2}$ doses achieved a sustained increase of CD25 expression of $20.46 \% \pm 5.20 \%(n=4)$, $31.09 \% \pm 10.32 \%(n=8)$, and $34.72 \%(n=2)$, respectively (Figure $4 \mathrm{~F})$. The increase of the dose interval to greater than 3 days resulted in loss of the Treg CD25 response at the time points assessed (Figure 4F). The changes in Treg proportion and CD25 expression from baseline were dependent on both dose and frequency $\left(\mathrm{R}^{2}=0.054, P<0.0001\right)$.

There was no clear effect of dose on Teffs at 3-day dosing intervals, with doses of $0.09,0.20,0.32$, and $0.47 \times 10^{6} / \mathrm{m}^{2}$ achieving percentage increases from baseline of $-1.58 \%(n=1),-6.74 \% \pm 5.11 \%(n=4)$, $-4.51 \% \pm 23.08 \%(n=8)$, and $12.07 \%(n=2)$, respectively (Figure $4, \mathrm{G}-\mathrm{I})$. 
115 patients accessed for eligibility

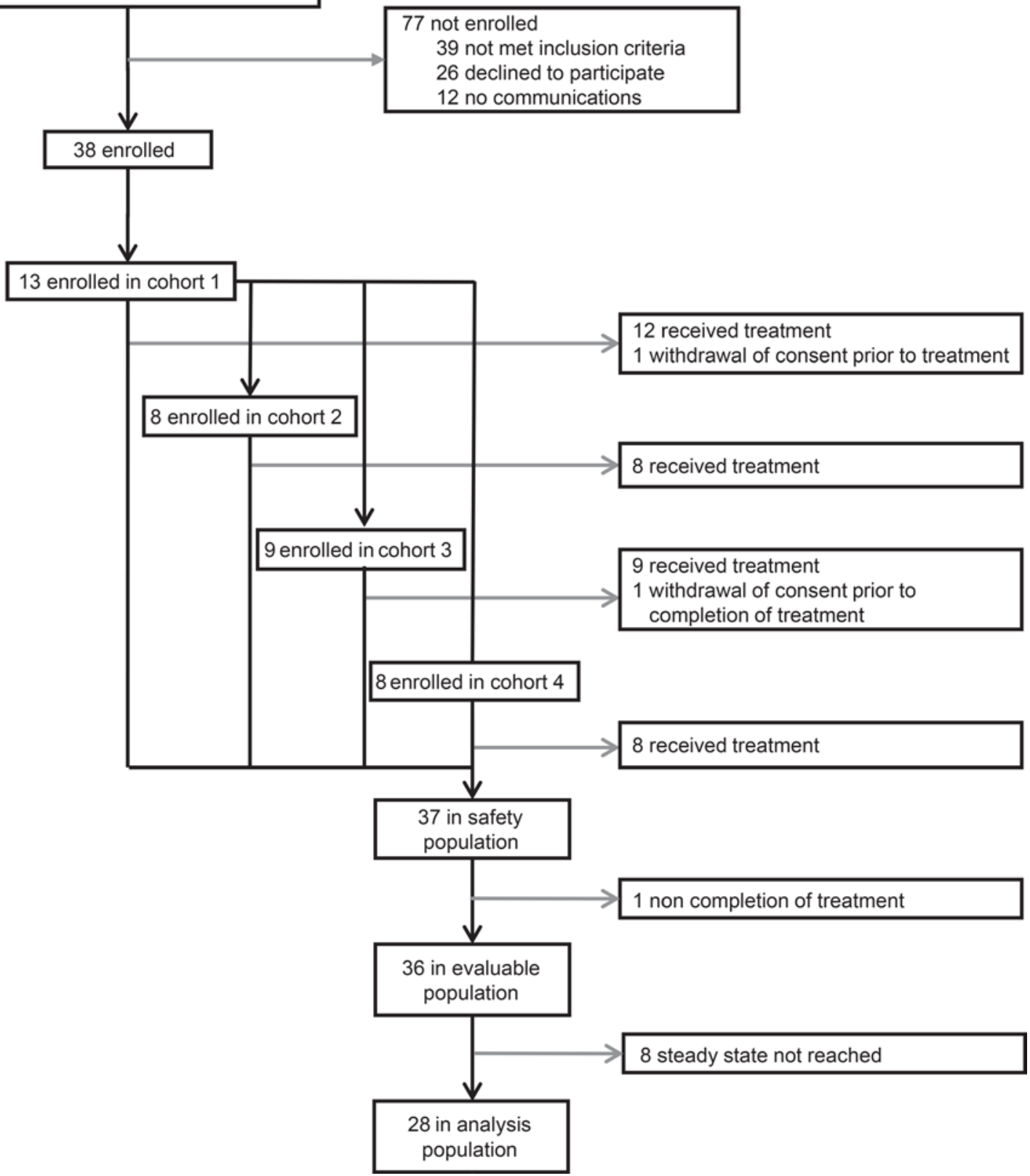

Figure 1. Trial profile

Prior to treatment, IL-2 levels in participants $(n=36)$ were $0.0025 \pm 0.0019 \mathrm{IU} / \mathrm{ml}(41.82 \pm 30.91 \mathrm{fg} /$ $\mathrm{ml}$ ), comparable to those previously reported for healthy individuals and T1D patients (18). The maximal sustained increase in IL-2 was at the $0.47 \times 10^{6} / \mathrm{m}^{2}$ dose delivered every 2 days, with a mean increase from baseline to plateau (trough values before last 3 doses) of $0.0247 \mathrm{IU} / \mathrm{ml}$ (Supplemental Figure 26). At 3-day interval dosing, participants administered the $0.20 \times 10^{6} \mathrm{IU} / \mathrm{m}^{2}$ and $0.32 \times 10^{6} \mathrm{IU} / \mathrm{m}^{2}$ doses had mean IL-2 increases at plateau of $0.0003 \pm 0.0003 \mathrm{IU} / \mathrm{ml}(n=4)$ and $0.0029 \pm 0.0038 \mathrm{IU} / \mathrm{ml}(n=8)$, respectively (Figure $5 \mathrm{~A})$. A single participant had an isolated IL-2 peak of $2.95 \mathrm{IU} / \mathrm{ml}$ on visit 6 that corresponded on review with an episode of gastroenteritis that was recorded as an AE (Figure 5A); this increase in endogenous IL-2 is similar to what we have previous measured in acute self-limiting viral gastroenteritis (19). The overall effect of the repeated doses of $0.20 \times 10^{6} \mathrm{IU} / \mathrm{m}^{2}$ and $0.32 \times 10^{6} \mathrm{IU} / \mathrm{m}^{2}$ aldesleukin every 3 days was to increase IL-2 levels by $18.75 \% \pm 21.38 \%(n=4)$ and $162.23 \% \pm 165.57 \%(n=8)$ above baseline at plateau. At the 5 -day interval 
Table 1. Baseline characteristics of safety population $(n=37)$

\begin{tabular}{|c|c|c|}
\hline \multicolumn{3}{|l|}{ Characteristic } \\
\hline \multirow[t]{2}{*}{ Age (yr) } & Mean (SD) & $38.2( \pm 11.2)$ \\
\hline & Median (min-max) & $36(19-65)$ \\
\hline \multirow[t]{2}{*}{ Age group } & $18-35 \mathrm{yr}$ & $15(40.5 \%)$ \\
\hline & $36-65 \mathrm{yr}$ & $22(59.5 \%)$ \\
\hline \multirow[t]{2}{*}{ Sex } & Male & $22(59.5 \%)$ \\
\hline & Female & $15(40.5 \%)$ \\
\hline \multirow[t]{2}{*}{ Diabetes duration (mo) } & Mean (SD) & $20.85( \pm 13.70)$ \\
\hline & Median (min-max) & $21.1(1.3-59.1)$ \\
\hline \multirow[t]{3}{*}{ Diabetes duration } & $\leq 100 \mathrm{~d}$ & $1(2.7 \%)$ \\
\hline & $>100 \mathrm{~d}$ and $\leq 2 \mathrm{yr}$ & $20(54.1 \%)$ \\
\hline & $>2 \mathrm{yr}$ and $\leq 5 \mathrm{yr}$ & $16(43.2 \%)$ \\
\hline \multirow[t]{2}{*}{ Age at diagnosis (yr) } & Mean (SD) & $36.5( \pm 11.3)$ \\
\hline & Median (min-max) & 35 (17-61) \\
\hline \multirow[t]{2}{*}{ BMI $\left(\mathrm{kg} / \mathrm{m}^{2}\right)$} & Mean (SD) & $23.878( \pm 3.369)$ \\
\hline & Median (min-max) & 23.88 (19.27-33.27) \\
\hline \multirow[t]{2}{*}{$\operatorname{BSA}\left(m^{2}\right)$} & Mean (SD) & $1.804( \pm 0.197)$ \\
\hline & Median (min-max) & $1.75(1.47-2.20)$ \\
\hline \multirow[t]{4}{*}{ Type 1 diabetes-associated Ab } & Anti-islet positive & $12(32.4 \%)$ \\
\hline & Anti-GAD positive & $31(83.8 \%)$ \\
\hline & Anti-IA2 positive & $15(41.7 \%)$ \\
\hline & Anti-ZnT8 positive & $19(52.8 \%)$ \\
\hline \multirow[t]{2}{*}{ Thyroid-associated Ab } & Anti-TPO positive & $8(22.2 \%)$ \\
\hline & Anti-TSH positive & $0(0 \%)$ \\
\hline \multirow[t]{2}{*}{ Plasma glucose (mmol/l) } & Mean (SD) & $9.60( \pm 3.76)$ \\
\hline & Median (min-max) & $9.1(3.5-18.1)$ \\
\hline \multirow[t]{2}{*}{ 1,5 Anhydroglucitol ( $\mu \mathrm{cg} / \mathrm{ml})$} & Mean (SD) & $6.32( \pm 5.50)$ \\
\hline & Median (min-max) & $4.43(0.96-26.15)$ \\
\hline \multirow[t]{2}{*}{ HbA1c (mmol/mol) } & Mean (SD) & $59.4( \pm 17.5)$ \\
\hline & Median (min-max) & $56(34-100)$ \\
\hline \multirow[t]{2}{*}{ HbA1c (\%) } & Mean (SD) & $7.584( \pm 1.603)$ \\
\hline & Median (min-max) & $7.27(5.26-11.30)$ \\
\hline \multirow[t]{2}{*}{ Insulin (pmol/l) } & Mean (SD) & $284.6889( \pm 544.4443)$ \\
\hline & Median (min-max) & $93.353(0.000-3032.323)$ \\
\hline \multirow[t]{2}{*}{ Proinsulin (pmol/l) } & Mean (SD) & $3.0769( \pm 3.8757)$ \\
\hline & Median (min-max) & $2.049(0.000-16.012)$ \\
\hline \multirow[t]{2}{*}{ C-peptide (pmol/l) } & Mean (SD) & $290.8( \pm 239.3)$ \\
\hline & Median (min-max) & $225(0-949)$ \\
\hline \multirow[t]{2}{*}{ Daily insulin dose (Units/kg body weight) } & Mean (SD) & $0.425( \pm 0.240)$ \\
\hline & Median (min-max) & $0.38(0-1.15)$ \\
\hline
\end{tabular}

only, the $0.47 \times 10^{6} \mathrm{IU} / \mathrm{m}^{2}$ dose produced an increase of $0.0005 \mathrm{IU} / \mathrm{ml}(n=2)$, when measured 5 days after each dose, while there was no increase with lower doses or at 10- or 14-day intervals (Figure 5, B and C). IL-2 levels observed at the measured time points are consistent with the single-dose levels observed in our previous study (18), with no evidence of drug accumulation or unexpected drug elimination due to the induction of receptor-mediated clearance. Creatinine levels and liver enzymes were within normal range (Supplemental Tables 4 and 5), indicating that IL-2 levels were not affected by renal or liver function.

At 90 minutes following the first dose, there was a dose-dependent increase in IL-2 levels that ranged from 0.7487 to $13.9685 \mathrm{IU} / \mathrm{ml}(n=28$, dose coefficient $=18.25, P<0.001)$, consistent with those observed in the previous single-dose study (DILT1D) (18). There was no difference in the levels of IL-2 at 90 minutes after the second dose of either $0.09 \times 10^{6} \mathrm{IU} / \mathrm{m}^{2}$ or $0.47 \times 10^{6} \mathrm{IU} / \mathrm{m}^{2}$, with mean increase of $1.43 \pm 0.48 \mathrm{IU} / \mathrm{ml}(n=7)$ and $7.97 \pm 4.00 \mathrm{IU} / \mathrm{ml}(n=9)$, respectively (Figure $5 \mathrm{D})$. To assess if the increase of Tregs and CD25 expression at steady state would alter IL-2 levels, they were measured 90 

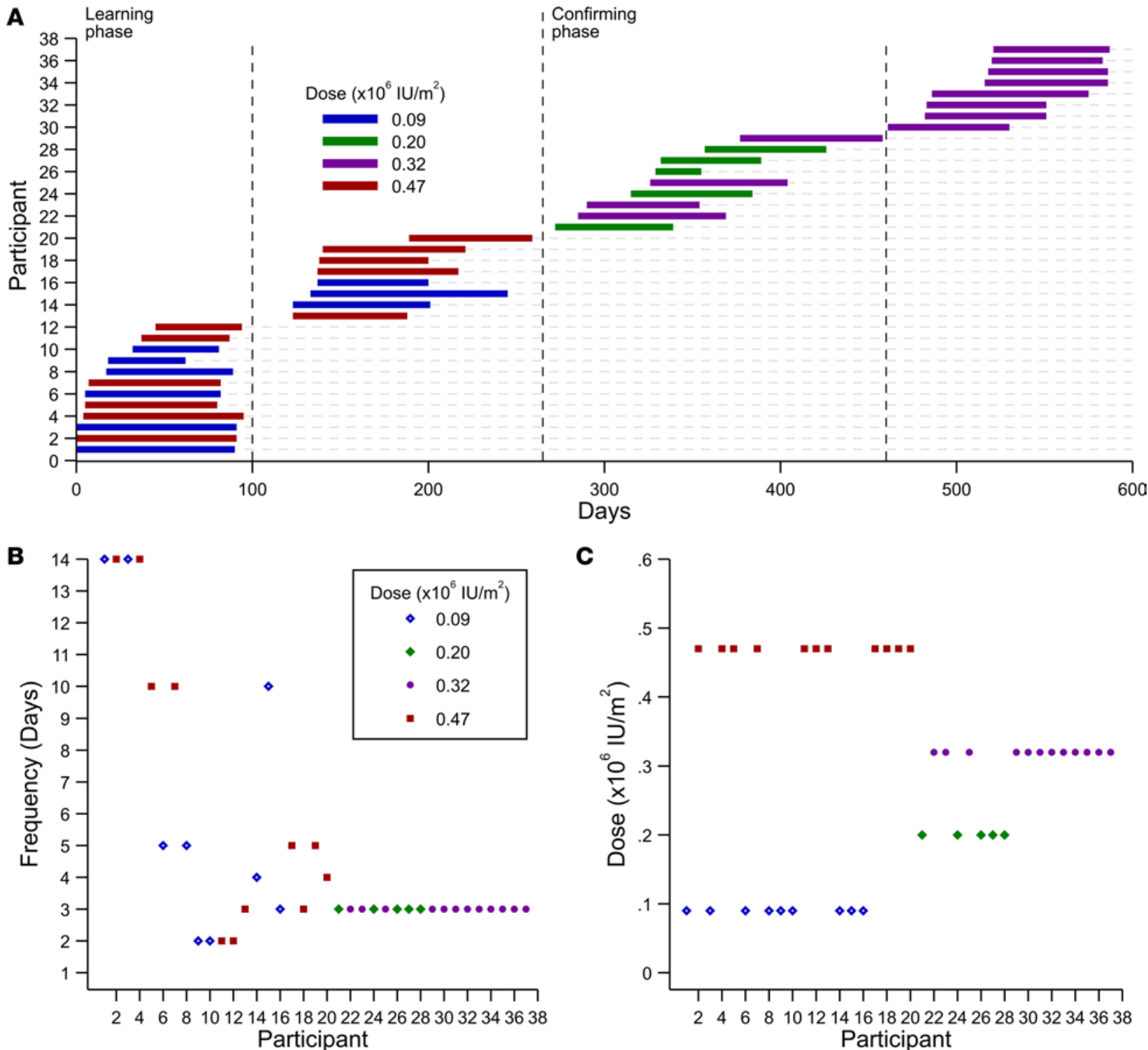

Figure 2. DILfrequency adaptive design, dose, and frequency allocation. (A) The study was conducted in 2 phases, a learning phase (259 days) and confirming phase (315 days). In the first learning phase, participants were allocated either $0.47 \times 10^{6} \mathrm{IU} / \mathrm{m}^{2}$ or $0.09 \times 10^{6} \mathrm{IU} / \mathrm{m}^{2}$ doses of aldesleukin, with sequential allocations of the longest dose interval first. After the first 12 participants, an interim analysis was performed that determined the dose and frequency allocation for the next cohort of 8 participants. The process was then repeated after completion of each cohort, with dose-frequency allocations based on analysis of all data collected from previous cohorts. (B) Participant frequency allocation showing convergence of the trial to every 3-day administration. (C) Participant dose allocation showing convergence of the trial to the $0.02 \times 10^{6} \mathrm{IU} / \mathrm{m}^{2}$ and $0.32 \times 10^{6} \mathrm{IU} / \mathrm{m}^{2}$ dose to estimate the optimal dose.

minutes after the tenth dose of $0.2 \times 10^{6} \mathrm{IU} / \mathrm{m}^{2}$ and $0.32 \times 10^{6} \mathrm{IU} / \mathrm{m}^{2}$ on visit 11 , with mean increases of $5.77 \pm 2.02 \mathrm{IU} / \mathrm{ml}(n=4)$ and $6.26 \pm 2.41 \mathrm{IU} / \mathrm{ml}(n=8)$, respectively (coefficient $=0.20, P=$ 0.7001 ) (Figure $5 \mathrm{D}$ ), thereby establishing that the immune system will be recurrently exposed to transient non-Treg-specific levels (>0.015 ml/IU) (18) after administration. Simultaneously, at 90 minutes, there was a rapid transient reduction in the percentage of Tregs in circulation $(-1.36 \% \pm 0.60 \% ; n=28)$ after the first dose; this reduction was observed again following the second $(-1.46 \% \pm 0.57 \% ; n=16)$ or tenth dose $(-1.81 \% \pm 0.53 \% ; n=12)$ when Tregs reached steady state (Figure $5 \mathrm{E})$. Though the proportion of Tregs trafficking out of the circulation remained similar regardless of the number of doses administered, the reduction in Treg count was greater at steady state (Figure $5 \mathrm{~F}$ ).

The Treg count was $54.9 \pm 22.6 \mu 1 / \mathrm{ml}(n=28)$ before treatment, with the mean increase from baseline of $17.3 \pm 7.9 \mathrm{cells} / \mu \mathrm{l}(n=4), 30.0 \pm 13.5 \mathrm{cells} / \mu \mathrm{l}(n=8)$, and $29.5 \mathrm{cells} / \mu \mathrm{l}(n=2)$ at doses of $0.20,0.32$ and $0.47 \times 10^{6} / \mathrm{m}^{2}$ every 3 days, respectively (Figure $6 \mathrm{~A}$ ). The increase in Treg count was only observed 
Table 2. AEs by severity and type in the safety population $(n=37)$

\begin{tabular}{|c|c|c|c|}
\hline Type of AE & Category & Events & Participants \\
\hline \multirow[t]{5}{*}{ Total } & Serious adverse events ( $n / \%)$ & $0(0 \%)$ & $0(0 \%)$ \\
\hline & Adverse events & $694(100 \%)$ & $37(100 \%)$ \\
\hline & AEs events by severity & & \\
\hline & Mild & $670(96.5 \%)$ & 37 (100\%) \\
\hline & Moderate & $24(3.5 \%)$ & $13(35.1 \%)$ \\
\hline \multirow[t]{31}{*}{ Related AEs } & Related AEs by severity ( $n / \%)$ & & \\
\hline & Mild & 474 (99.0\%) & $35(94.6 \%)$ \\
\hline & Moderate & $5(1.0 \%)$ & $3(8.1 \%)$ \\
\hline & All related $A E s$ & & \\
\hline & Acne & $2(0.4 \%)$ & $2(5.4 \%)$ \\
\hline & Asthenic condition & $3(0.6 \%)$ & $3(8.1 \%)$ \\
\hline & Dry eye & $1(0.2 \%)$ & $1(2.7 \%)$ \\
\hline & Eosinophilia & $1(0.2 \%)$ & $1(2.7 \%)$ \\
\hline & Injection site erythema & $230(48.0 \%)$ & 35 (94.6\%) \\
\hline & Injection site nodule & $234(48.9 \%)$ & $33(89.2 \%)$ \\
\hline & Malaise & $1(0.2 \%)$ & $1(2.7 \%)$ \\
\hline & Migraine headaches & $1(0.2 \%)$ & $1(2.7 \%)$ \\
\hline & Nasopharyngitis & $3(0.6 \%)$ & $3(8.1 \%)$ \\
\hline & Nausea and vomiting symptoms & $2(0.4 \%)$ & $2(5.4 \%)$ \\
\hline & Oropharyngeal pain & $1(0.2 \%)$ & $1(2.7 \%)$ \\
\hline & Related AEs ( $n / \%)$ by & & \\
\hline & Expected & 472 (98.5\%) & 35 (94.6\%) \\
\hline & Unexpected & $7(1.5 \%)$ & $5(13.5 \%)$ \\
\hline & Related AEs by cohort & & \\
\hline & Cohort 1 & & \\
\hline & Mild & $112(100 \%)$ & $11(91.7 \%)$ \\
\hline & Moderate & $0(0 \%)$ & $0(0 \%)$ \\
\hline & Cohort 2 & & \\
\hline & Mild & $100(98 \%)$ & $7(87.5 \%)$ \\
\hline & Moderate & $2(2 \%)$ & $1(12.5 \%)$ \\
\hline & Cohort 3 & & \\
\hline & Mild & $121(98.4 \%)$ & $9(100 \%)$ \\
\hline & Moderate & $2(1.6 \%)$ & $1(11.1 \%)$ \\
\hline & Cohort 4 & & \\
\hline & Mild & 141 (99.3\%) & $8(100 \%)$ \\
\hline & Moderate & $1(0.7 \%)$ & $1(12.5 \%)$ \\
\hline \multirow[t]{2}{*}{ Hypoglycemia } & Events per no. of glucose measurements & $94 / 9159(1 \%)$ & \\
\hline & Events per no. of participants & & $20(54.1 \%)$ \\
\hline
\end{tabular}

when aldesleukin was administered every 2, 3, or 5 days. The change in Treg counts from baseline to steady state was dose-frequency dependent $\left(\mathrm{r}^{2}=0.4108, P=0.0130\right.$, Figure $6, \mathrm{~B}$ and $\left.\mathrm{C}\right)$. Within the Treg population, both naive and memory Tregs were increased by $49.89 \% \pm 47.25 \%(n=27)$ and $39.60 \% \pm 36.45 \%$ $(n=28)$, respectively, from baseline to steady state, with the $0.2 \times 10^{6} \mathrm{IU} / \mathrm{m}^{2}$ and $0.32 \times 10^{6} \mathrm{IU} / \mathrm{m}^{2}$ doses resulting in the greatest increases of effector memory Tregs $(91.07 \% \pm 44.05 \%, n=12)$ (Figure $6 \mathrm{D})$. Within the rest of the CD4 compartment, there was no effect of dose or frequency of administration on total CD4 $\left(r^{2}=0.1640, P=0.3680\right)$ or CD4 T effector counts $\left(r^{2}=0.1582, P=3890\right)$. Similarly, there was no change in NK cell count from baseline to steady state $(0.028 \mathrm{cell} / \mu \mathrm{l} ; \pm 0.072 ; n=28)$, with no dose-frequency response $\left(\mathrm{r}^{2}=0.1564, P=0.3957\right)$ (Supplemental Figures 4-14 and 19-25).

Metabolic control remained stable throughout the trial, with fasting C-peptide slightly increasing from baseline to the final measurement by $26.75 \% \pm 68.42 \%(n=25)$, with no effect of dose or frequency of aldesleukin administration observed (Figure 7, A-C). 1,5 Anhydroglucitol, a marker for short-term glucose control; the proinsulin-to-C-peptide ratio, a marker for $\beta$ cell stress; and random glucose remained stable with a baseline change of $17.63 \% \pm 42.65 \%(n=23), 6.07 \% \pm 44.34 \%(n=16)$, and $7.99 \% \pm 36.92 \%(n=26)$, respectively. 


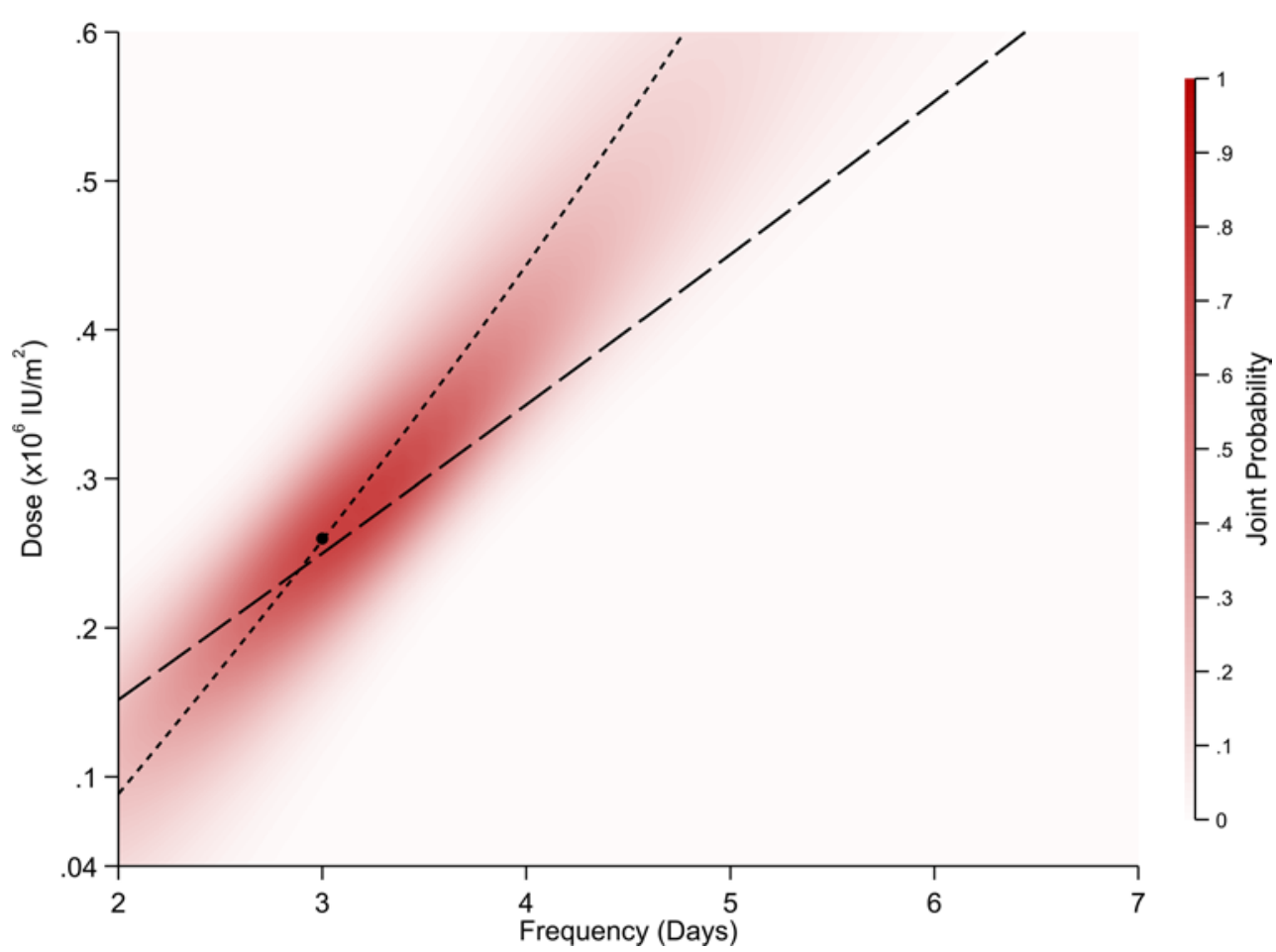

Figure 3. Primary endpoints. This statistical model described the Treg and Treg CD25 dose-frequency response best, with the larger dashed line showing the dose frequencies predicted to achieve increases from baseline of 30\% for Tregs and smaller dashed line showing a 25\% increase for Treg CD25. The dot marks the optimal dose frequency with the joint probability of achieving shown as a red density plot.

Insulin use at baseline and follow-up was $0.421 \pm 0.227$ units $/ \mathrm{kg}(n=27)$ and $0.464 \pm 0.193$ units $/ \mathrm{kg}(n=26)$, respectively (Figure 7, D-F). Baseline and follow-up HbA1c were $56.1 \pm 15.5 \mathrm{mmol} / \mathrm{mol}(n=28)$ and 51.6 $\pm 12.3 \mathrm{mmol} / \mathrm{mol}(n=28)$, respectively, meaning that there was small improvement in blood glucose control $(-4.71 \% \pm 8.55 \%, n=28)$ (Supplemental Figure 27).

\section{Discussion}

The DILfrequency study has established the optimal dose and administration frequency to maintain an increase in Tregs and Treg CD25 expression while not expanding Teffs in participants with T1D. A response-adaptive design has been employed to develop an immunomodulatory treatment protocol that increases immune regulation within physiological levels to restore health while preserving pathogen responses in participants with T1D. This experimental medicine approach of defining a treatment regimen based on our understanding of the immunopathogenesis of the disease prior to testing clinical efficacy contrasts with current strategies of conducting traditional randomized, double-blind placebo control trials that test efficacy first with limited success $(20,21)$.

The adaptive-response design of DILfrequency defined the "optimal" dose frequency to achieve the trial targets by continuously adapting the dose and frequency after each interim analysis. This methodology allowed for the flexibility to adapt to a wider range of dose frequencies than could be pragmatically investigated in a fixed dose study of a similar size. By focusing the analysis on patients who had reached a stable steady state, the probability to define the optimal treatment regimen was further increased. This enabled the development of a regimen where $0.26 \times 10^{6} \mathrm{IU} / \mathrm{m}^{2}$ aldesleukin every 3 days should result in the targeted expansion of Tregs by $30 \%$ and an increase of Treg CD25 by $25 \%$ without increasing Teffs.

Lower doses and/or lower frequencies induced an attenuated or even no response of Tregs, while higher doses and/or higher frequencies risk Treg desensitization and expansion of Teffs and are less practical for patients. While both frequency and dose were crucial to reach the targeted expansion, frequency seemed to be even more decisive, as shown by the relatively tight CI compared with the dose. This regimen of aldesleukin differs from other schemes, currently administered in T1D clinical trials, where a 5-day induction treatment $\left(0.5 \times 10^{6}\right.$ to $1 \times 10^{6} \mathrm{IU} / \mathrm{d}$ for children or $1 \times 10^{6} \mathrm{IU} / \mathrm{d}$ for adults $)$ is followed by a single 
A

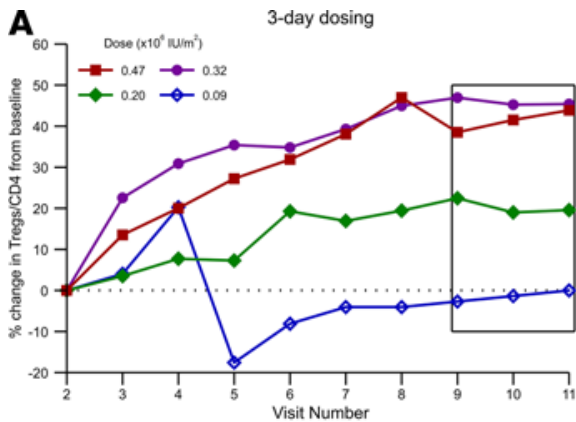

D

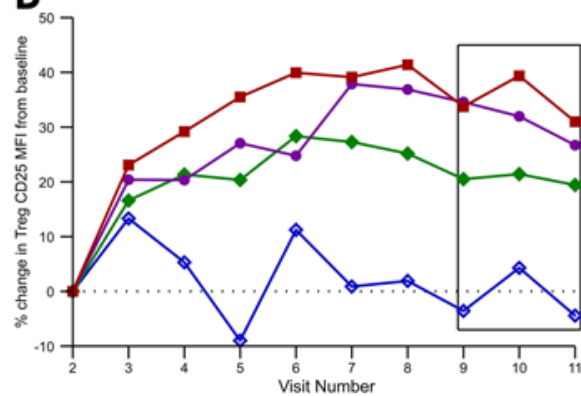

G

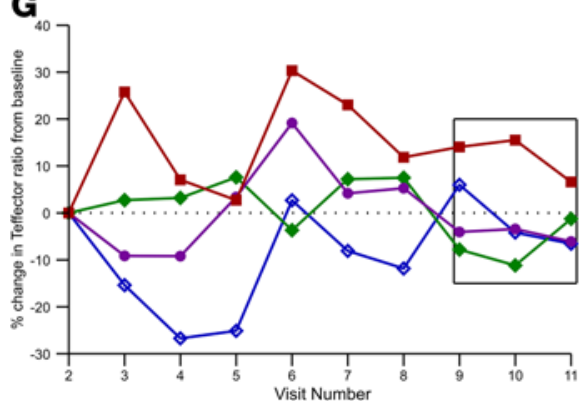

B

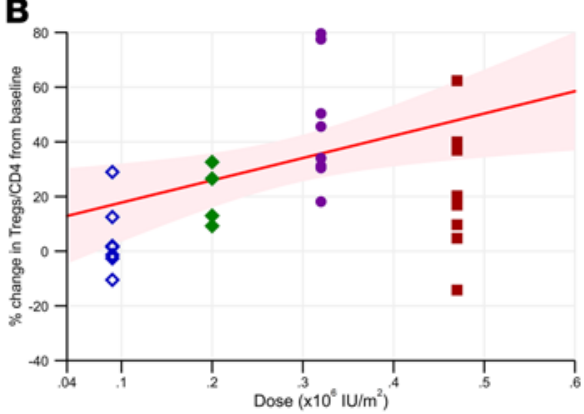

E

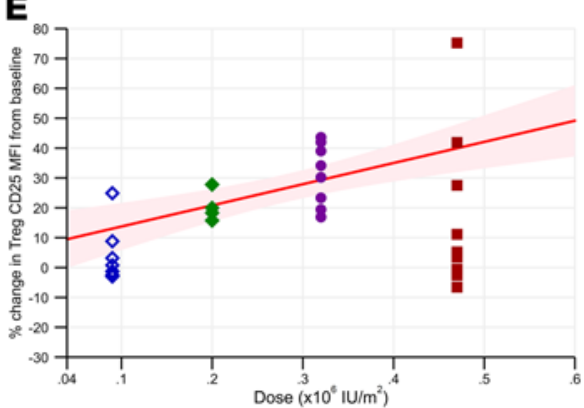

H

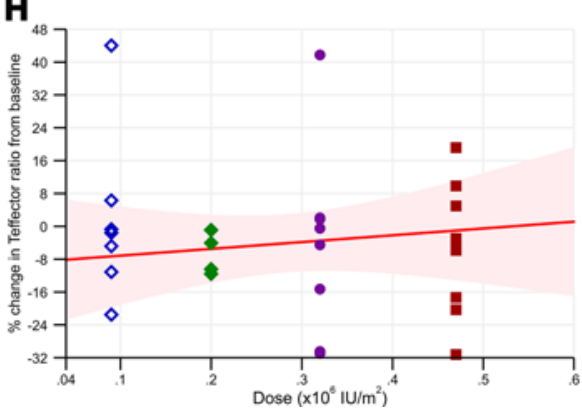

C

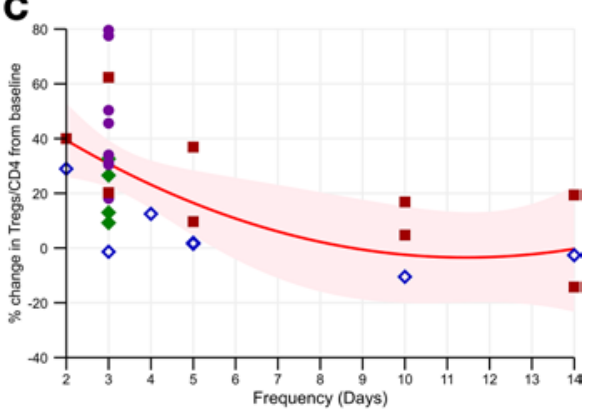

$\mathbf{F}$

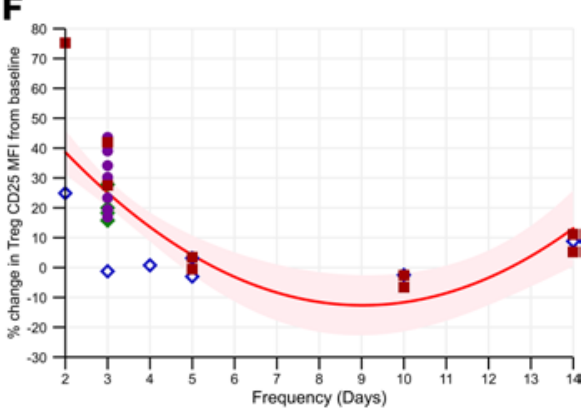

I

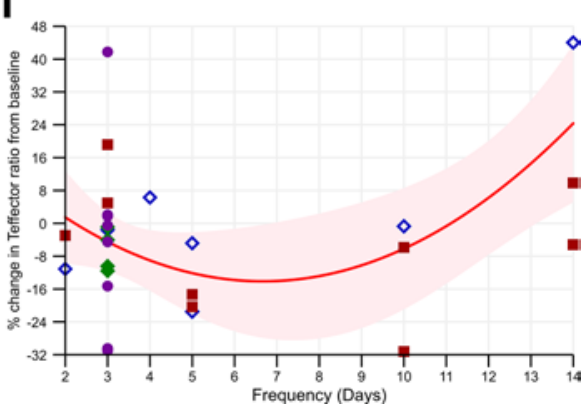

Figure 4. Treg, Treg CD25, and T effector responses to aldesleukin treatment. (A) Treg proportions as a percentage of CD4+ $T$ cells for doses administered every 3 days, with the box highlighting the final 3 trough values at steady state that were used to define the Treg primary endpoint (average response plots shown across the 4 doses; $n=1$ for $0.09 \times 10^{6} \mathrm{IU} / \mathrm{m}^{2}, n=4$ for $0.2 \times 10^{6} \mathrm{IU} / \mathrm{m}^{2}, n=8$ for $0.32 \times 10^{6} \mathrm{IU} / \mathrm{m}^{2}, n=2$ for $\left.0.47 \times 10^{6} \mathrm{IU} / \mathrm{m}^{2}\right)$. Visit number $2(x$ axis) depicts first dosing visit. (B) The percentage change in Tregs at the primary endpoint for all doses administered, with the predicted dose response at the best frequency (every 3 days, red line) showing an increase in precision of the estimates around the optimal dose for the whole analysis population $\left(0.26 \times 10^{6} \mathrm{IU} / \mathrm{m}^{2}\right.$, shaded area $\left.95 \% \mathrm{CI}\right)$. (C) The increase in Tregs for all frequencies allocated, with the predicted frequency response at the optimal dose $\left(0.26 \times 10^{6} \mathrm{IU} / \mathrm{m}^{2}\right.$, red line) showing increased precision of the estimates around day 3. (D) Increase in CD25 expression on Tregs at the 3-day frequency at the primary endpoint (average response plots shown across the 4 doses; $n=1$ for $0.09 \times 10^{6} \mathrm{IU} / \mathrm{m}^{2}, n=4$ for $0.2 \times 10^{6} \mathrm{IU} / \mathrm{m}^{2}, n=8$ for $0.32 \times 10^{6} \mathrm{IU} / \mathrm{m}^{2}, n=2$ for $0.47 \times 10^{6} \mathrm{IU} / \mathrm{m}^{2}$ ). (E and $\mathbf{F}$ ) The change in Treg CD25 at all doses and frequencies, with increased precision of the estimates around the 3-day frequency (red line). (G) The changes in the T effector (Teff) ratio of the proportion naive effectors to memory effectors at the 3 -day frequency (average response plots shown across the 4 doses; $n=1$ for $0.09 \times 10^{6} \mathrm{IU} / \mathrm{m}^{2}, n=4$ for $0.2 \times 10^{6} \mathrm{IU} / \mathrm{m}^{2}, n=8$ for $0.32 \times 10^{6} \mathrm{IU} / \mathrm{m}^{2}, n=2$ for $\left.0.47 \times 10^{6} \mathrm{IU} / \mathrm{m}^{2}\right)$. (H and I) The change in Teff ratio at the primary endpoint at all doses and frequency, showing no dose-frequency response at $0.26 \times 10^{6} \mathrm{IU} / \mathrm{m}^{2}$ every 3 days.

dose every 7 or 14 days, dependent on treatment cohort (22). Our regimen is similar to a dosing regimen $\left(0.1 \times 10^{6}\right.$ to $0.2 \times 10^{6} \mathrm{IU} / \mathrm{m}^{2} 3$ times per week) that was utilized to treat another clinical population, namely pediatric patients after allogeneic hematopoietic stem cell transplantation (23).

Treatment with these doses and frequencies of aldesleukin used in DILfrequency was well tolerated, with most common AEs being mild injection site reactions, and all infections were self-limiting. Eosinophilia, a well-known side effect of IL-2 treatment, only occurred asymptomatically in a single participant receiving the highest dose repeatedly, while preexisting eosinophilia in 2 other participants improved or even resolved. Another side effect of IL-2 treatment, especially in cancer treatment, is the development of autoimmune diseases, such as thyroiditis (24). No secondary autoimmune diseases were triggered, even in participants with high preexisting risks, such as TPO-autoantibody positivity. Moreover, we were able to observe in detail how a case of preexisting psoriasis remained stable throughout the trial (25). Overall, the aldesleukin treatment regimen had a favorable safety profile, which is essential for any potential therapy in T1D. 


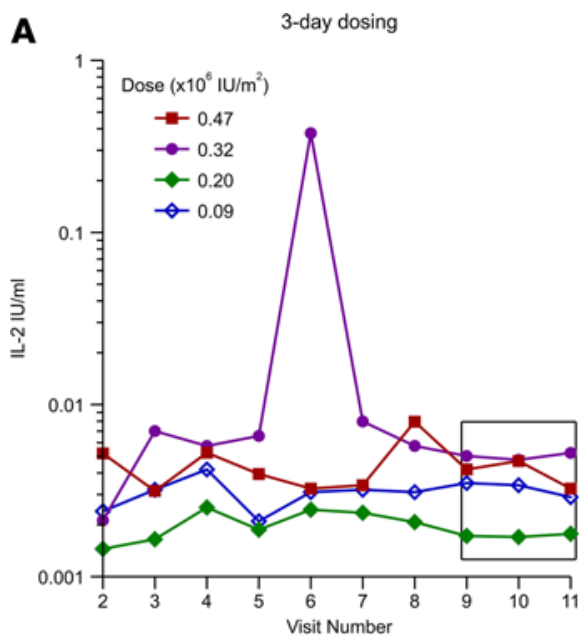

D

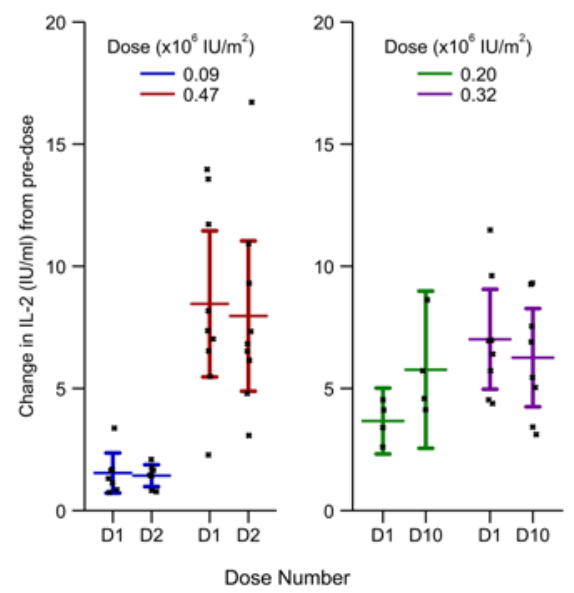

B

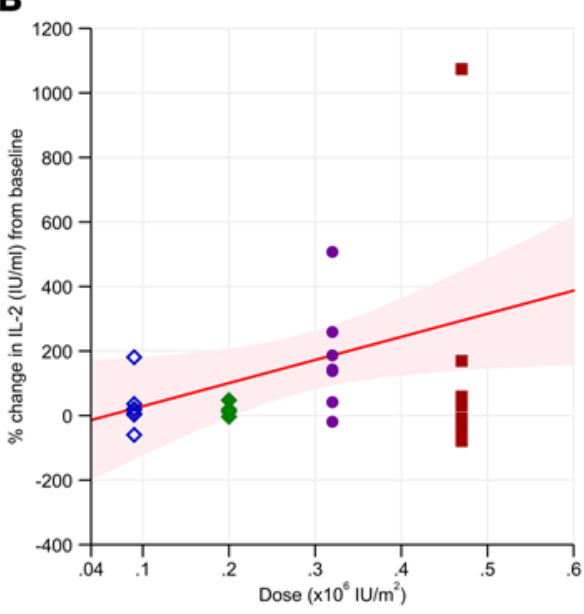

E

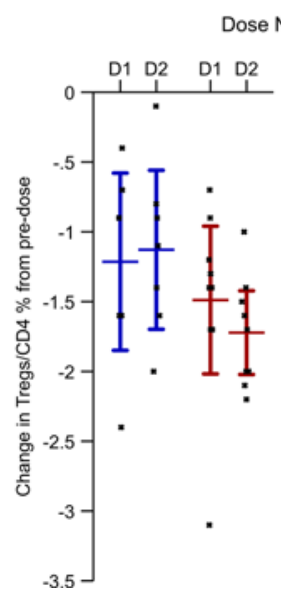

c

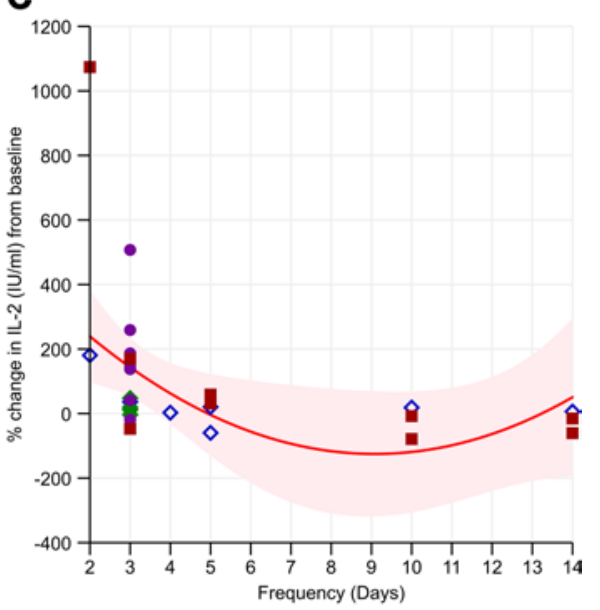

$\mathbf{F}$

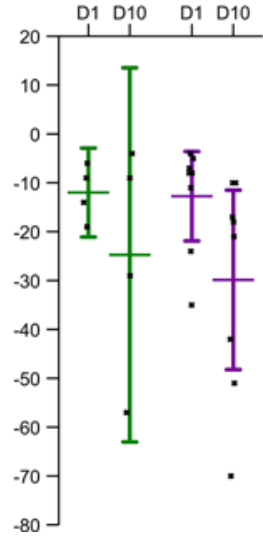

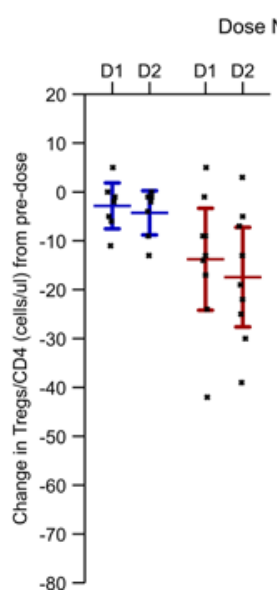

Dose Number

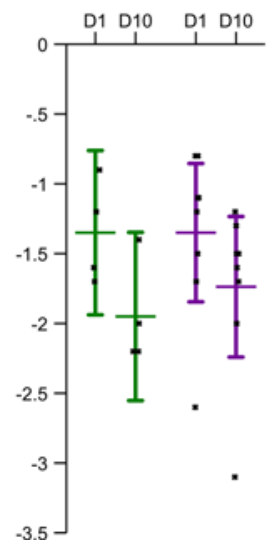

Figure 5. IL-2 levels and hyperacute Treg responses. (A) IL-2 levels during treatment with aldesleukin every 3 days, with the box highlighting the final 3 trough values. The peak on visit 6 in the $0.32 \times 10^{6}$ dose group is coincident with the report of an adverse event (gastroenteritis) from a participant (average response plots shown across the 4 doses; $n=1$ for $0.09 \times 10^{6} \mathrm{IU} / \mathrm{m}^{2}, n=4$ for $0.2 \times 10^{6} \mathrm{IU} / \mathrm{m}^{2}, n=8$ for $0.32 \times 10^{6} \mathrm{IU} / \mathrm{m}^{2}, n=2$ for $\left.0.47 \times 10^{6} \mathrm{IU} / \mathrm{m}^{2}\right)$. Visit number 2 ( $x$ axis) depicts the first dosing visit. (B and $\mathbf{C}$ ) The percentage change in IL-2 levels from baseline and at the measurement of the primary endpoint in the whole analysis population for all doses, with the estimated dose response at the best frequency (every 3 days, red line) and the optimal dose $\left(0.26 \times 10^{6} \mathrm{lU} / \mathrm{m}^{2}\right.$, red line, shaded area $\left.95 \% \mathrm{CI}\right)$. (D) Change in IL-2 levels at 90 minutes following the first dose (D1), the second dose (D2), or the tenth dose (D10) ( $n=7$ for $0.09 \times 10^{6} \mathrm{IU} / \mathrm{m}^{2}, n=4$ for $0.2 \times 10^{6} \mathrm{IU} / \mathrm{m}^{2}, n=8$ for $0.32 \times 10^{6} \mathrm{IU} / \mathrm{m}^{2}$, and $n=9$ for $\left.0.47 \times 10^{6} \mathrm{IU} / \mathrm{m}^{2}\right)$. (E) The decline in Tregs proportions as a percentage of CD4 $4^{+}$cells at 90 minutes $\left(n=7\right.$ for $0.09 \times 10^{6} \mathrm{IU} / \mathrm{m}^{2}, n=4$ for $0.2 \times 10^{6} \mathrm{IU} / \mathrm{m}^{2}, n=8$ for $0.32 \times 10^{6} \mathrm{IU} / \mathrm{m}^{2}$, and $n=9$ for $\left.0.47 \times 10^{6} \mathrm{IU} / \mathrm{m}^{2}\right)$. (F) The decline in Treg counts at 90 minutes at the commencement of treatment and when Tregs have increased by dose 10 (visit 11$)\left(n=7\right.$ for $0.09 \times 10^{6}$ $\mathrm{IU} / \mathrm{m}^{2}, n=9$ for $0.47 \times 10^{6} \mathrm{IU} / \mathrm{m}^{2}, n=4$ for $0.2 \times 10^{6} \mathrm{IU} / \mathrm{m}^{2}$, and $n=8$ for $\left.0.32 \times 10^{6} \mathrm{IU} / \mathrm{m}^{2}\right)$. Data represent mean values, and error bars show $95 \% \mathrm{Cl}$.

In DILfrequency, administration of repeated doses of $0.47 \times 10^{6} \mathrm{IU} / \mathrm{m}^{2}$ aldesleukin every 2 days, increased IL-2 levels to a plateau above the Treg-specific level of $0.015 \mathrm{IU} / \mathrm{ml}$ and could activate Teff cells (18), while the IL-2 concentrations at the $0.2 \times 10^{6} \mathrm{IU} / \mathrm{m}^{2}$ and $0.32 \times 10^{6} \mathrm{IU} / \mathrm{m}^{2}$ doses every 3 days were increased above pretreatment levels. Previously, we observed that IL-2 levels increased to peak concentrations that are not selective for Tregs at 90 minutes and 24 hours after administration of aldesleukin (18). Here, we found that these peak drug concentrations at 90 minutes were replicated at all doses and frequencies, even after several administrations when Tregs had expanded to a steady state. This suggests that there is minimal target-mediated drug disposition/clearance induced by the dosing regimens tested.

There was a transient decrease in both Treg percentage and count in the circulation at $90 \mathrm{~min}$ utes, consistent with our previous observation following a single dose of aldesleukin where Tregs were decreased at 90 minutes and at 24 hours following dosing. This could indicate increased retention of Tregs in the tissues or vasculature upon aldesleukin administration or recruitment of Tregs from the blood to tissue or both. Interestingly, once Tregs had expanded in response to the repeated aldesleukin doses, the reduction in the number of Tregs in the circulation at 90 minutes increased, though the percentage 
A

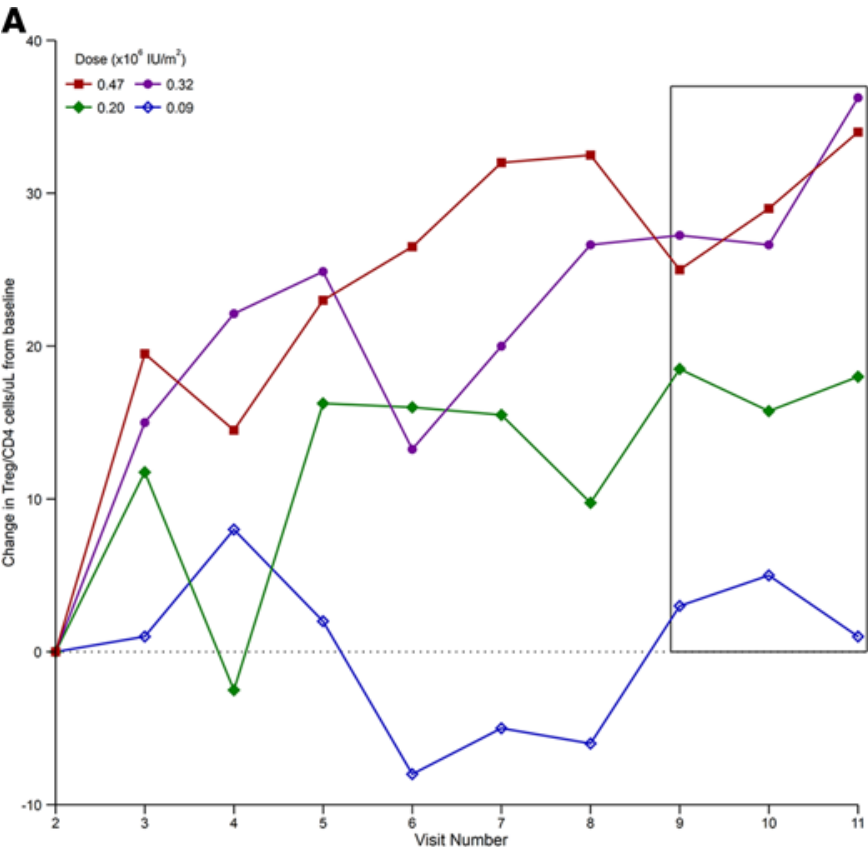

C

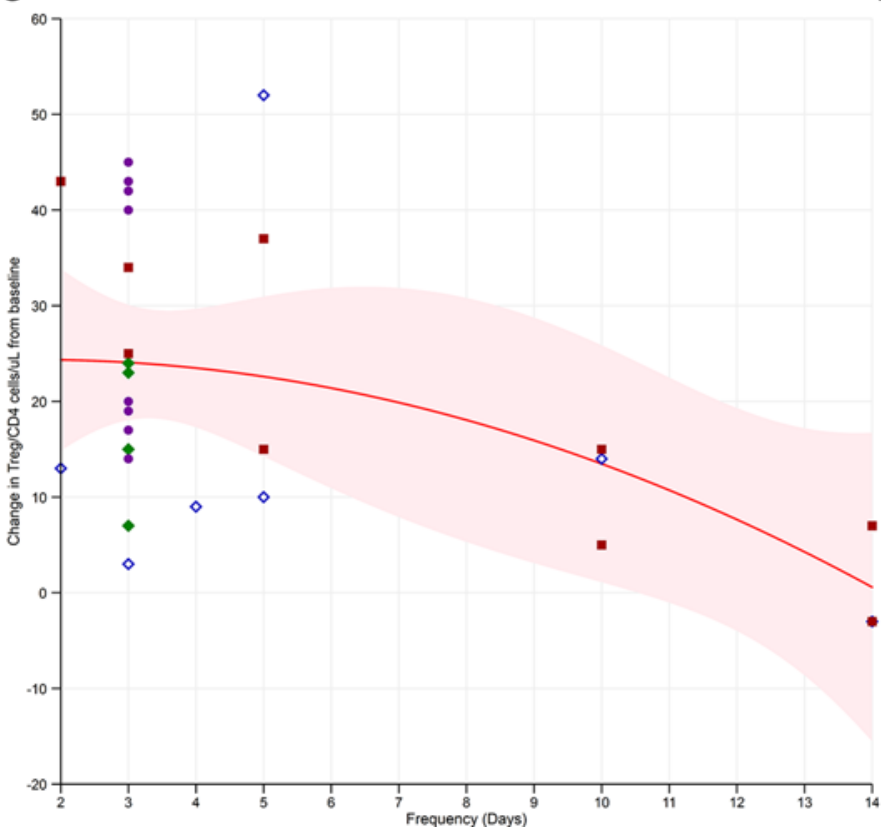

B

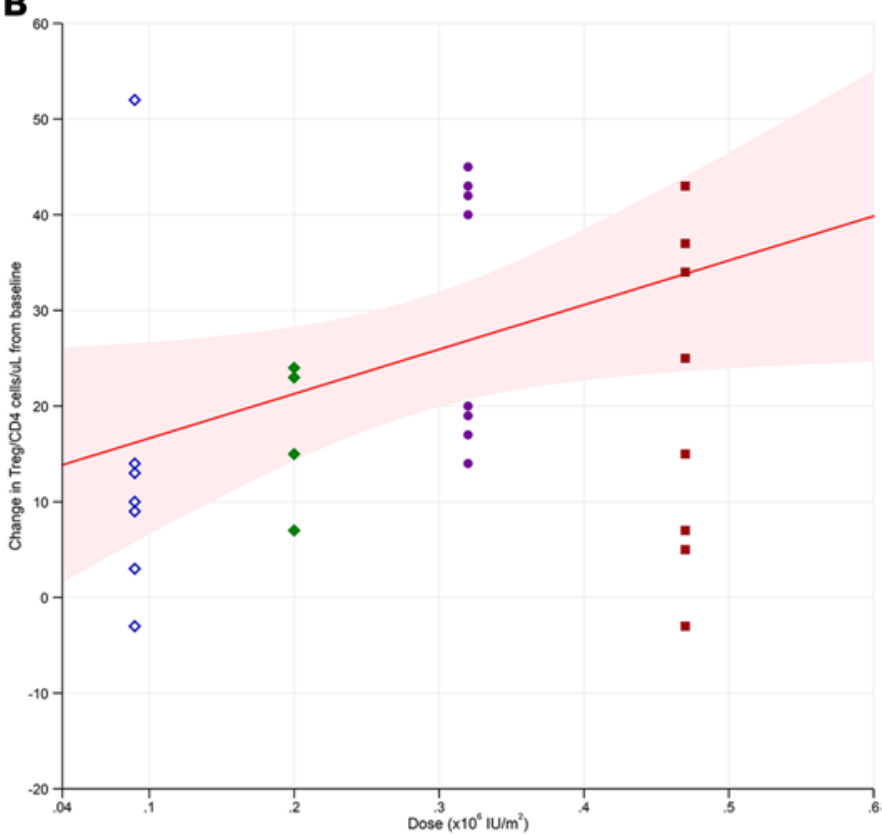

D

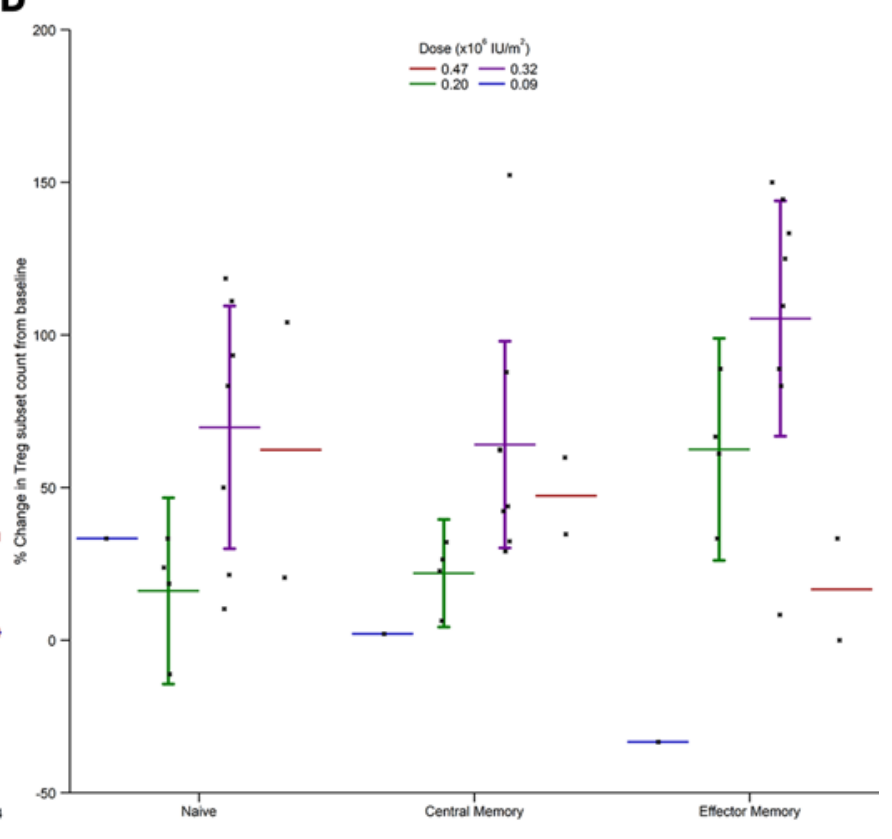

Figure 6. Treg counts and subsets. (A) Treg counts during treatment with aldesleukin every 3 days, with the box highlighting the final 3 trough values. Visit number 2 ( $x$ axis) depicts the first dosing visit (average response plots shown across the 4 doses; $n=1$ for $0.09 \times 10^{6} \mathrm{IU} / \mathrm{m}^{2}, n=4$ for $0.2 \times 10^{6} \mathrm{IU} / \mathrm{m}^{2}, n=8$ for $0.32 \times 10^{6} \mathrm{IU} / \mathrm{m}^{2}$, and $n=2$ for $\left.0.47 \times 10^{6} \mathrm{IU} / \mathrm{m}^{2}\right)$. (B and C) The changes in Treg count at all doses and frequencies allocated showing the estimated dose response when aldesleukin is administered every 3 days (red line) and frequency response at $0.26 \times 10^{6} \mathrm{IU} / \mathrm{m}^{2}$ (red line, shaded area $95 \% \mathrm{Cl}$ ). (D) The change in Treg subsets from baseline to measurement of the primary endpoint $\left(\mathrm{Naive}: n=1\right.$ for $0.09 \times 10^{6} \mathrm{IU} / \mathrm{m}^{2}, n=4$ for $0.2 \times 10^{6} \mathrm{IU} / \mathrm{m}^{2}, n=7$ for $0.32 \times 10^{6} \mathrm{IU} / \mathrm{m}^{2}, n=2$ for $0.47 \times 10^{6} \mathrm{IU} / \mathrm{m}^{2}$; Central Memory: $n=1$ for $0.09 \times 10^{6} \mathrm{IU} / \mathrm{m}^{2}, n=4$ for $0.2 \times 10^{6} \mathrm{IU} / \mathrm{m}^{2}, n=8$ for $0.32 \times 10^{6} \mathrm{IU} / \mathrm{m}^{2}, n=2$ for $0.47 \times 10^{6} \mathrm{IU} / \mathrm{m}^{2}$; Effector Memory: $n=1$ for $0.09 \times 10^{6} \mathrm{IU} / \mathrm{m}^{2}, n=4$ for $0.2 \times 10^{6} \mathrm{IU} / \mathrm{m}^{2}, n=8$ for $0.32 \times 10^{6} \mathrm{IU} / \mathrm{m}^{2}, n=2 \mathrm{for}$ $\left.0.47 \times 10^{6} \mathrm{IU} / \mathrm{m}^{2}\right)$. Data represent mean values, and error bars show $95 \% \mathrm{Cl}$.

decrease $(\sim 20 \%)$ was unchanged from initial visits. This suggests that there is a Treg population that retains its original sensitivity to aldesleukin. Further detailed analyses are required to understand the immunophenotype and function of these Tregs. The measurement of Treg count also enabled a comparison with the responses to IL-2 treatment in cGVHD where there is partial clinical efficacy (26). In cGVHD, the pretreatment Treg count was approximately 3 -fold lower than that observed in T1D and increased after 12 weeks of treatment $\left(1 \times 10^{6} \mathrm{IU} / \mathrm{m}^{2} / \mathrm{d}\right)$ to a Treg plateau within the range achieved 


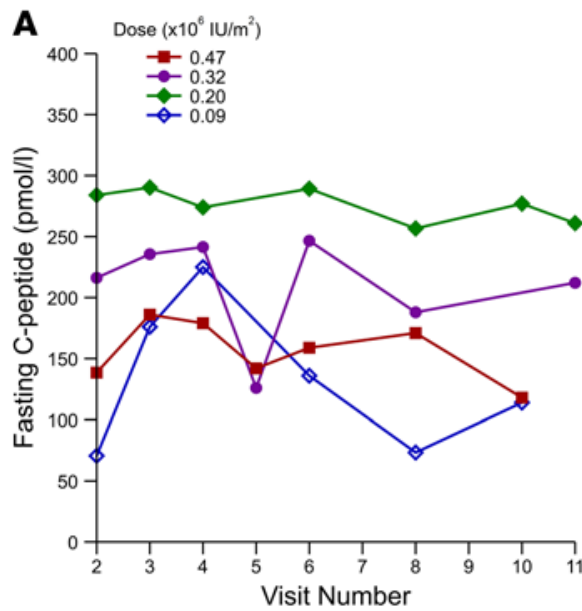

B
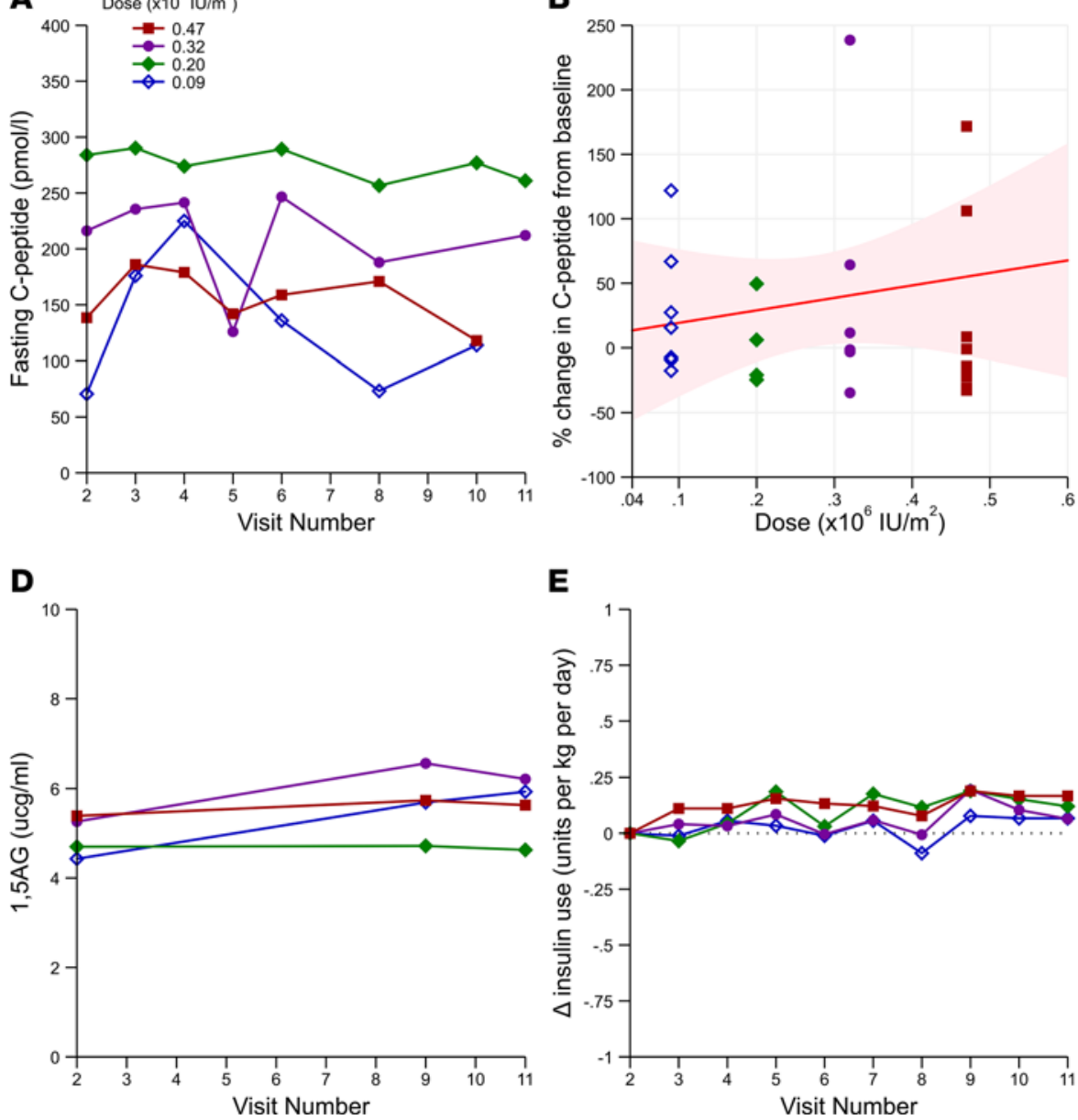

$\mathbf{E}$

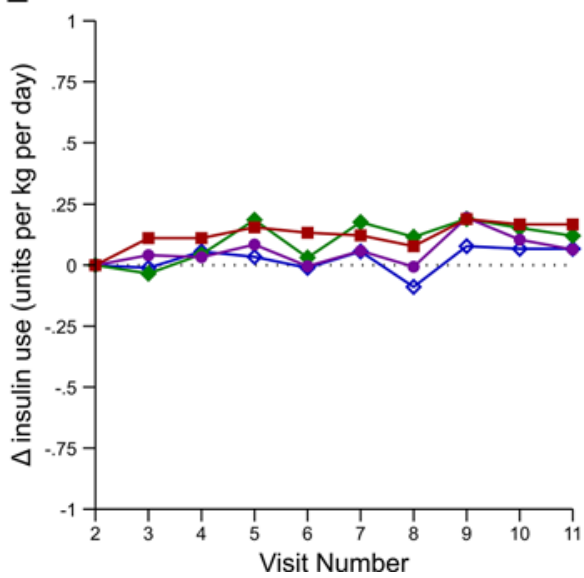

C

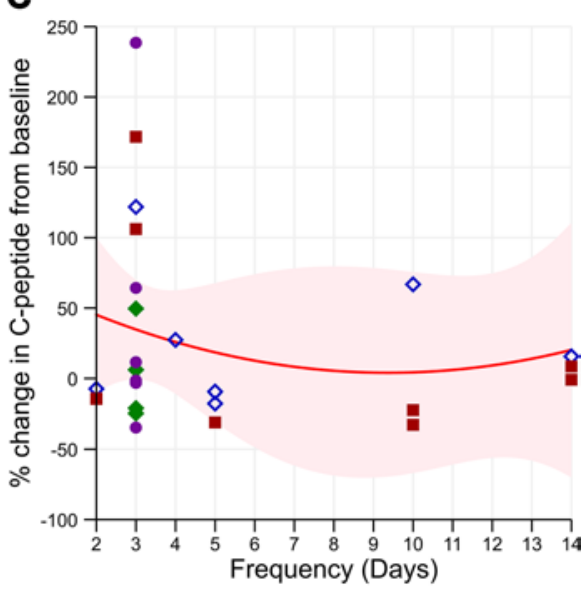

$\mathbf{F}$

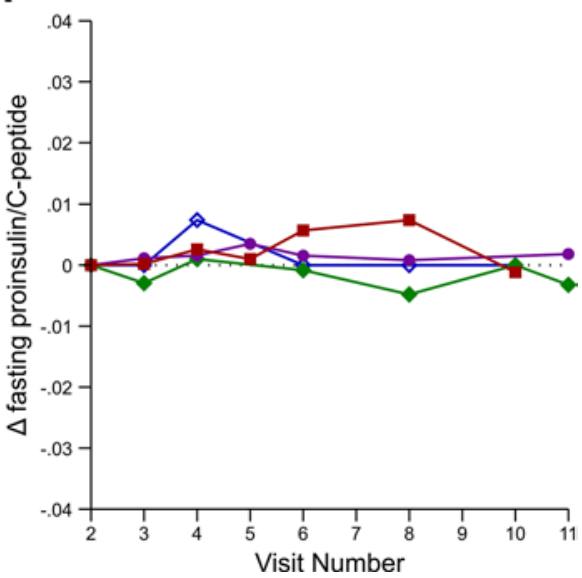

Figure 7. Metabolic parameters. (A) Fasting C-peptide levels before treatment and during treatment. Visit number 2 ( $x$ axis) depicts the first dosing visit. (B and $\mathbf{C}$ ) The percentage change in fasting and nonfasting C-peptide levels for all allocated dose frequencies, with the predicted dose response at the best frequency ( 3 days, red line, shaded area $95 \% \mathrm{CI}$ ) and frequency response at the optimal dose $\left(0.26 \times 10^{6} \mathrm{IU} / \mathrm{m}^{2}\right.$, red line). (D) 1,5 -Anhydroglucitol level before and during treatment, with increased levels representing better glycemic control. (E and F) Insulin use and fasting proinsulin to C-peptide ratio for all doses administered every 3 days (average response plots shown across the 4 doses for the whole analysis population).

in DILfrequency with 3-day dosing. These more intensive aldesleukin regimes may be required for the autoinflammatory orders, such as cGVHD and systemic lupus erythematosus where there is a reduction Treg count as compared with T1D where Treg function alone is impaired $(12,15)$.

DILfrequency was a mechanistic trial designed to develop an optimal IL-2 treatment regimen for T1D based on a primary immunological outcome rather than metabolic efficiency. The informativeness of the metabolic endpoints measured are limited, owing to the short period of treatment, but did show that there was no evidence of adverse alterations of these metabolic parameters or evidence of $\beta$ cell stress. There was a small increase of endogenous fasting C-peptide (27) and stable glucose homeostasis with no change in insulin usage by participants in the trial. The analysis of the trial was also limited to peripheral blood from adult T1D patients due to ethical and practical considerations.

In DILfrequency, an adaptive design has been successfully employed to develop a well-tolerated, IL-2-intermittent dosing regimen of $0.26 \times 10^{6} \mathrm{IU} / \mathrm{m}^{2}$ aldesleukin every 3 days that targets and maintains homeostatic Treg responses without inducing short-term immunosuppression. The clinical efficacy of this self-administered treatment can now be evaluated in a substantially larger trial using a longer duration of the optimized dosing regimen in T1D patients with residual insulin production to determine if these immunomodulatory effects will induce remission from $\beta$ cell autoimmunity, leading to preservation of endogenous insulin production to improve clinical outcomes. Furthermore, the effect of the disease background and baseline values could be integrated in analysis of future trials to broaden our understanding of the effect of IL-2 on immune outcomes. This optimized treatment regimen of low-dose aldesleukin may now be evaluated in a 
clinical trial with metabolic primary endpoints. The findings of this mechanistic trial will also inform future drug development targeting the IL-2 pathway, especially the next generation of extended half-life Treg-specific molecules (28). Moreover, the trial methodologies that we developed can be employed in first-in-human-studies with other immunological drugs to immediately access proof of mechanism in patients, thereby leading to a more efficient and safe drug development, since fewer patients would be exposed to risk.

\section{Methods}

Study design and participants. This was a single-center, nonrandomized, open-label, response-adaptive trial of repeated doses of aldesleukin in participants with T1D. The trial commenced with a learning phase, in which 12 participants were allocated doses and frequencies at the extremes of the available combinations. The dose and frequency for the learning phase were informed by the results of the preceding single dose DILT1D trial (18). The next 3 cohorts of 8 participants were planned to form a tripartite confirming phase. After each cohort completed, all data accumulated in the trial were analyzed by the trial statisticians. From the interim reports, the DFC provided decisions regarding the choice of dose and frequency to administer to the subsequent cohorts. The decision-making process of allocating treatment was defined prior to the first meeting of the DFC (Supplemental Appendix, DFC charter).

The study team employed an internet recruitment strategy to enroll eligible participants from across the European Union (29). Treatment and follow up was performed at the National Institute for Health Research/Wellcome Trust Clinical Research Facility, Addenbrooke's Hospital. Participants were eligible if they were aged 18 to 70 years and had a duration of T1D of $\leq 5$ years from diagnosis. Key exclusion criteria were unstable diabetes with recurrent hypoglycemia, active clinical infection, active autoimmune thyroid disease, history of severe organ dysfunction, malignancy, and history or current or past use of immunosuppressive agents (Supplemental Appendix, Inclusion criteria and Exclusion criteria).

Procedures. Participants were enrolled for 6-16 weeks depending on treatment duration. All participants had 12 visits, including a screening visit, 5-10 treatment visits (dependent on dose-frequency allocation), and a follow-up visit at approximately 4 weeks after the final dose of drug. For the first learning phase, subcutaneous doses of $0.09 \times 10^{6} \mathrm{IU} / \mathrm{m}^{2}$ and $0.47 \times 10^{6} \mathrm{IU} / \mathrm{m}^{2}$ aldesleukin were administered to cohort 1 every $2,5,10$, or 14 days.

Target ranges for the coprimary endpoints were determined by the DFC based on the data acquired during the learning phase. Doses and frequencies for the subsequent 3 cohorts were determined by the DFC based on results of interim analyses. Aldesleukin (Novartis Pharmaceuticals UK Ltd) was prepared by the clinical trial pharmacy at Addenbrooke's Hospital and either administered by a nurse or self-administered under observation (Supplemental Appendix, Study drug administration and Drug storage and supply). Samples of blood were taken immediately before drug administration for immunophenotyping, full blood counts, and inflammatory markers at all visits. The baseline sample (pretreatment) was drawn just before administration of the first dose on visit 2, with further samples obtained on following visits within 1 hour before or after the time recorded on visit 2 . To characterize the hyperacute effects of aldesleukin, blood samples were also drawn at 90 minutes after administration of the drug after the first, second, and/or tenth dose. For metabolic assays, samples were obtained in fasting or nonfasting state depending on cohort and visit number.

The FACS assay was performed on whole blood following good clinical practice at the Department of Clinical Immunology, Addenbrooke's Hospital within 4 hours of phlebotomy. Full blood counts, clinical chemistry, metabolic measures (HbA1c, C-peptide, insulin, proinsulin, 1,5 anhydroglucitol), thyroid function tests, and autoantibodies (anti-islet, anti-GAD, anti-IA2, anti-ZNT8, anti-TPO, anti-TSH receptor antibodies) were measured at the Departments of Haematology, Biochemistry and Immunology, Addenbrooke's Hospital. IL-2 was measured using the MSD S-PLEX Human IL-2 assay (limit of detection 2 fg/ $\mathrm{ml}$ ) at MSD and converted to IU/ml (30). Safety was assessed at all visits by adverse event reporting, clinical examination, vital signs, and review of the study diary containing daily glucose values and insulin use. A single participant with a previous history of psoriasis had 2 skin punch biopsies of inflammatory lesions, 1 during the dosing period (visit 10) and 1 during the follow-up visit (visit 12).

Outcomes. The coprimary endpoints are the percentage change in Tregs, Teffs, and CD25 expression on Tregs from baseline to the average of the last 3 values immediately preceding drug administration (trough values) when steady state has been achieved. Tregs, Teffs, and CD25 expression on Tregs were defined within the $\mathrm{CD}^{+} \mathrm{CD}^{+}$FACS gate (Supplemental Appendix, Coprimary endpoints - definitions). The detailed gating strategy has been previously published (31). Secondary predefined clinical endpoints were 
change in Treg count and subsets, T effector count and subsets, NK cell frequency and count, full blood count and differential, IL-2 and hsCRP levels, autoantibodies, metabolic measures, and safety. An exploratory endpoint was the effect of aldesleukin on psoriatic plaques. Prespecified endpoints were limited to parameters that could be reproducibly measured following good clinical practice to make clinical decisions.

Data availability statement. The data cannot be anonymized sufficiently to be able to be put in the public domain without the risk of participant identification. Data are available on request through the Cambridge University institutional repository (https://www.repository.cam.ac.uk/handle/1810/265634).

Statistics. Three populations were predefined for the analyses. The safety population includes all participants who received any dose of aldesleukin. The evaluable population includes participants who received all treatments, where coprimary endpoints were measured. The analysis population includes a subset of the evaluable population, where the 3 coprimary endpoints were observed at steady state and used for all primary, secondary, and exploratory analysis. Steady state was achieved if the trough value(s) of the percentage increase of Tregs, CD25, or Teffs did not have an upward or downward trend at the end of the dosing schedule. The targets for the coprimary endpoints were set by the DFC after the learning phase. For the primary analysis, a multivariate regression model was fitted with the coprimary endpoints as the dependent variables. The relationship between dose and frequency was analyzed in candidate models, with the best model having the smallest Akaike information criterion.

The calculated dose/frequency to achieve the target increases in Treg and CD25 was obtained by setting the linear predictors for Treg and CD25 to equal the targets and solving the simultaneous equations for dose and frequency. The precision to which dose can be administered is $0.01 \times 10^{6} \mathrm{IU} / \mathrm{m}^{2}$ and practically frequency can only be integer days, meaning that the predicted calculated dose/frequency to achieve the increases is unlikely to be practical. Therefore, the joint probability that all 3 coprimary endpoints fell within the target ranges was calculated for each dose/frequency able to be practically administered. In addition to the joint probability, the Mahalanobis distance, a measure of how close each dose/frequency is to achieving the targets in Treg and CD25, was calculated. The practical dose/frequency that maximized the joint probability was selected as the optimal dose/frequency, if the Teffs at this administration were predicted to be within the target range. The optimal dose/frequency is reported in the Results.

For the secondary endpoints, two measures were defined, the change and the percentage change. The change is the difference between the baseline and time point measurements. The percentage change is defined as the ratio of the change to the baseline measurement. For the 90-minute variable, a linear mixed-effects model was fitted with the outcome defined as the difference between the measurement and the corresponding trough value, with dose, frequency, and dosing visit included as covariates in the model as well as a random intercept with participant as the grouping variable. For the other derived variables, a univariate regression model was fitted, including the same covariates as the primary analysis model. As the effects of dose and frequency cannot be separated, the $\mathrm{R}^{2}$ value and a global $\mathrm{F}$ test were reported to evaluate how much of the variability in the endpoint is explained by dose and frequency. Where the secondary outcome measures were not measured repeatedly at each visit, the same measures were defined at visit 12 . Continuous variables are expressed as mean $\pm \operatorname{SD}(n)$, with the $\operatorname{SD}$ only reported when $n \geq 4$, and discrete variables are expressed as count (\%).

The DILfrequency trial is an exploratory study, which was not designed to formally test a hypothesis in a confirmatory fashion, so no statement of statistical significance is made, though $P$ values are provided to the reader (see the Supplemental Appendix, SAP plan).

Study approval. The study was performed in accordance with the guidelines for good clinical practice and the Declaration of Helsinki. Approval was obtained from the Health Research Authority, National Research Ethics Service (14/EE/1057), London, United Kingdom. The trial was registered at the International Standard Randomised Controlled Trial Number Register (ISRCTN40319192) and ClinicalTrials. gov (NCT02265809). The study protocol was published in advance of the completion and final analysis of the trial (31). All participants provided written informed consent prior to their participation in the study.

\section{Author contributions}

FWL served as the chief investigator and wrote the first draft of the manuscript; other members of the writing team included ES, JH, APM, and SB. JH, APM, and SB performed the study analysis. ES, JH, LP, LT, JH, JK, ELA, KA, NMW, RA, MLP, ER, ME, LSW, JAT, APM, SB, and FWL were involved in the conduct of the study and collection of the data, participated in the review of the article, and approved the final version. 
FWL had full access to all the data, carried out the analysis of the primary and secondary outcomes with JH and SB (trial statisticians) and had the final responsibility for the decision to submit to publication

\section{Acknowledgments}

Funding was provided by the Sir Jules Thorn Trust, the Swiss National Science Foundation, Wellcome, JDRF, and NIHR Cambridge Biomedical Research Centre. The study was sponsored by the University of Cambridge and Cambridge University Hospital Trust. The authors acknowledge the support of the NIHR Cambridge Biomedical Research Centre and the Cambridge Clinical Trial Unit for trial coordination; the NIHR/Wellcome Trust Clinical Research Facility and Addenbrooke's Centre for Clinical Investigation for clinical facilities; the Department of Clinical Immunology, Addenbrooke's Hospital; the JDRF/Wellcome Trust Diabetes and Inflammation laboratory sample processing team (led by Helen Stevens) and information technology and administration team (led by Judy Brown) and data teams at the Cambridge Institute for Medical Research; Laurence Peterson, JDRF/Wellcome Diabetes and Inflammation laboratory, Cambridge Institute for Medical Research; Sarah Bird for technical assistance; and Kevin O'Shaughnessy, Department of Medicine, University of Cambridge, independent chair of the DILfrequency trial steering committee. For assistance with identification of potential participants, we acknowledge the ADDRESS-2 study and colleagues at the Wolfson Diabetes and Endocrine Clinic, Addenbrooke's Hospital. The authors thank Ken Smith, Department of Medicine, University of Cambridge, for critical review of the manuscript. The generous contribution of the participants in DILfrequency is very gratefully acknowledged.

Address correspondence to: Frank Waldron-Lynch, Novartis Institutes for Biomedical Research, WSJ386.11.48.03, CH-4002, Basel, Switzerland. Email: frankwaldronlynch@gmail.com.

FWL's present address is: Novartis Institutes for Biomedical Research, Translational Medicine, Autoimmunity, Transplant, and Immunology, Basel, Switzerland.

1. Patterson CC, Dahlquist GG, Gyürüs E, Green A, Soltész G, EURODIAB Study Group. Incidence trends for childhood type 1 diabetes in Europe during 1989-2003 and predicted new cases 2005-20: a multicentre prospective registration study. Lancet. 2009;373(9680):2027-2033.

2. Tuomilehto J. The emerging global epidemic of type 1 diabetes. Curr Diab Rep. 2013;13(6):795-804.

3. Atkinson MA, Eisenbarth GS, Michels AW. Type 1 diabetes. Lancet. 2014;383(9911):69-82.

4. Lind M, et al. Glycemic control and excess mortality in type 1 diabetes. N Engl J Med. 2014;371(21):1972-1982.

5. Roep BO, Tree TI. Immune modulation in humans: implications for type 1 diabetes mellitus. Nat Rev Endocrinol. 2014;10(4):229-242.

6. Aronson R, et al. Low-dose otelixizumab anti-CD3 monoclonal antibody DEFEND-1 study: results of the randomized phase III study in recent-onset human type 1 diabetes. Diabetes Care. 2014;37(10):2746-2754.

7. Malek TR. The biology of interleukin-2. Annu Rev Immunol. 2008;26:453-479.

8. Sakaguchi S, Miyara M, Costantino CM, Hafler DA. FOXP3+ regulatory T cells in the human immune system. Nat Rev Immunol. 2010;10(7):490-500.

9. Garg G, et al. Type 1 diabetes-associated IL2RA variation lowers IL-2 signaling and contributes to diminished CD4+CD25+ regulatory T cell function. J Immunol. 2012;188(9):4644-4653.

10. Fyfe G, Fisher RI, Rosenberg SA, Sznol M, Parkinson DR, Louie AC. Results of treatment of 255 patients with metastatic renal cell carcinoma who received high-dose recombinant interleukin-2 therapy. J Clin Oncol. 1995;13(3):688-696.

11. Rosenberg SA, Yang JC, White DE, Steinberg SM. Durability of complete responses in patients with metastatic cancer treated with high-dose interleukin-2: identification of the antigens mediating response. Ann Surg. 1998;228(3):307-319.

12. Koreth J, et al. Interleukin-2 and regulatory T cells in graft-versus-host disease. N Engl J Med. 2011;365(22):2055-2066.

13. Saadoun D, et al. Regulatory T-cell responses to low-dose interleukin-2 in HCV-induced vasculitis. N Engl J Med. 2011;365(22):2067-2077.

14. Hordinsky M, Kaplan DH. Low-dose interleukin 2 to reverse alopecia areata. JAMA Dermatol. 2014;150(7):696-697.

15. He J, et al. Low-dose interleukin-2 treatment selectively modulates CD4(+) T cell subsets in patients with systemic lupus erythematosus. Nat Med. 2016;22(9):991-993.

16. Hartemann A, et al. Low-dose interleukin 2 in patients with type 1 diabetes: a phase $1 / 2$ randomised, double-blind, placebo-controlled trial. Lancet Diabetes Endocrinol. 2013;1(4):295-305.

17. Long SA, et al. Rapamycin/IL-2 combination therapy in patients with type 1 diabetes augments Tregs yet transiently impairs B-cell function. Diabetes. 2012;61(9):2340-2348.

18. Todd JA, et al. Regulatory $\mathrm{T}$ cell responses in participants with type 1 diabetes after a single dose of interleukin-2: a non-randomised, open label, adaptive dose-finding trial. PLoS Med. 2016;13(10):e1002139.

19. Cutler AJ, et al. Capturing the systemic immune signature of a norovirus infection: an n-of-1 case study within a clinical trial. Wellcome Open Res. 2017;2:28.

20. Waldron-Lynch F, et al. Rationale and study design of the adaptive study of IL-2 dose on regulatory T cells in type 1 diabetes 
(DILT1D): a non-randomised, open label, adaptive dose finding trial. BMJ Open. 2014;4(6):e005559.

21. Ehlers MR. Strategies for clinical trials in type 1 diabetes. J Autoimmun. 2016;71:88-96.

22. ESHHS Conference, July 12-14, 2017, in collaboration with SISS, University of Bari Aldo Moro. J Hist Behav Sci. 2017;53(4):401-402.

23. Kennedy-Nasser AA, et al. Ultra low-dose IL-2 for GVHD prophylaxis after allogeneic hematopoietic stem cell transplantation mediates expansion of regulatory $\mathrm{T}$ cells without diminishing antiviral and antileukemic activity. Clin Cancer Res. 2014;20(8):2215-2225.

24. Krouse RS, et al. Thyroid dysfunction in 281 patients with metastatic melanoma or renal carcinoma treated with interleukin-2 alone. J Immunother Emphasis Tumor Immunol. 1995;18(4):272-278.

25. Lee RE, Gaspari AA, Lotze MT, Chang AE, Rosenberg SA. Interleukin 2 and psoriasis. Arch Dermatol. 1988;124(12):1811-1815

26. Koreth J, et al. Efficacy, durability, and response predictors of low-dose interleukin-2 therapy for chronic graft-versus-host disease. Blood. 2016;128(1):130-137.

27. Besser RE, Jones AG, McDonald TJ, Shields BM, Knight BA, Hattersley AT. The impact of insulin administration during the mixed meal tolerance test. Diabet Med. 2012;29(10):1279-1284.

28. Cully M. Deal watch: IL-2 focus switches to stimulating Tregs. Nat Rev Drug Discov. 2017;16(9):595

29. Heywood J, et al. Effective recruitment of participants to a phase I study using the internet and publicity releases through charities and patient organisations: analysis of the adaptive study of IL-2 dose on regulatory T cells in type 1 diabetes (DILT1D). Trials. 2015;16:86.

30. Glezer EN, et al. Cytokine immunoassays with sub-fg/ml detection limits. AAPS 2014 National Biotechnology Conference https://www.mesoscale.com/ /media/files/scientific\%20poster/aaps 2014\%20\%20cytokine $\% 20 \% 20$ immunoassays.pdf. Accessed September 6, 2018.

31. Truman LA, et al. Protocol of the adaptive study of IL-2 dose frequency on regulatory T cells in type 1 diabetes (DILfrequency): a mechanistic, non-randomised, repeat dose, open-label, response-adaptive study. BMJ Open. 2015;5(12):e009799. 